\title{
Axial inhomogeneities in steady-state dissolved oxygen in airlift bioreactors: predictive models
}

\author{
Fernando Camacho Rubio $^{a}$, Jose Luis Garcia ${ }^{\mathrm{b}}$, Emilio Molina ${ }^{\mathrm{b}}$, Yusuf Chisti ${ }^{\mathrm{c}, *}$ \\ ${ }^{a}$ Department of Chemical Engineering, University of Granada, E-18071 Granada, Spain \\ ${ }^{\mathrm{b}}$ Department of Chemical Engineering, University of Almería, E-04071 Almería, Spain \\ ${ }^{\mathrm{c}}$ Institute of Technology and Engineering, Massey University, Palmerston North, New Zealand
}

Received 28 June 2000; received in revised form 11 September 2000; accepted 13 September 2000

\begin{abstract}
Models were developed for prediction and interpretation of the observed steady-state axial dissolved oxygen concentration profiles in tall airlift bioreactors. The observed concentration profiles were non-linear because of a combination of hydrodynamic and mass transport factors. The profiles were influenced mainly by the liquid-phase axial dispersion coefficient, the volumetric overall gas-liquid mass transfer coefficient, the gas velocity, the induced liquid circulation velocity. The model-predicted concentration profiles agreed within $\pm 2 \%$ with the measured data in a tall (working aspect ratio $\sim 15$ ) airlift vessel operated under aeration regimens that are typically used during wastewater treatment. Axial inhomogeneities in dissolved oxygen increased with increasing aeration rate. This phenomenon may influence activated sludge processes in airlift and deep-shaft reactors. The maximum attainable concentration of dissolved oxygen at the bottom of a typically aerated airlift reactor, $\geq 3.5 \mathrm{~m}$ deep, always remained at $<80 \%$ of air saturation value even when oxygen was not being consumed. Also, at steady state and without a net transfer of oxygen, the gas-phase mole fraction of oxygen varied by $>10 \%$ axially up the reactor. (C) 2001 Elsevier Science B.V. All rights reserved.
\end{abstract}

Keywords: Airlift bioreactors; Axial dispersion; Deep-shaft reactor; Hydrodynamics; Oxygen transfer

\section{Introduction}

Airlift bioreactors are used in advanced activated sludge processes for treating wastewater [1-5] and in the bioprocess industry [5]. The aspect ratio of airlift reactors typically exceeds 6 , but much greater aspect ratios are seen in wastewater treatment operations that rely on high hydrostatic pressure in a deep airlift column to enhance oxygen transfer $[2,5]$. Compared with conventional activated sludge processes, oxygen transfer rates in airlift devices are up to 10 -fold greater [4]. In addition to providing oxygen, sparged air provides the motive force for circulating wastewater and suspending microbial flocs. The observed rapid rates of waste degradation are linked to several factors, including fast oxygen transfer, long gas-liquid contact times, and intense turbulence in the circulating fluid. At peak load, the oxygen transfer rate approaches about $1 \mathrm{~kg} \mathrm{O}_{2} \mathrm{~m}^{-3} \mathrm{~h}^{-1}$ [3]. Under steady-state operation, spatial inhomogeneities in dissolved oxygen concentration have been observed in tall airlift vessels [2,5-7]. The inhomogeneities are espe-

\footnotetext{
${ }^{*}$ Corresponding author. Fax: +64-6-350-5604.

E-mail address: y.chisti@massey.ac.nz (Y. Chisti).
}

cially pronounced in the axial direction both in the riser and the downcomer zones. Variations in dissolved oxygen concentration potentially affect the local and the overall productivity of bioreactors; hence, quantification of axial changes in concentration is necessary. This paper develops models for predicting the nature of the steady-state axial profiles of dissolved oxygen in airlift bioreactors. The models are tested using data measured in a tall split-cylinder airlift device (aspect ratio $\sim 15$ ). The profiles are shown to be sensitive to several factors, particularly the liquid-phase axial dispersion coefficients in the riser and the downcomer, the aeration rate, the overall volumetric gas-liquid mass transfer coefficient, the liquid circulation rate, and other geometric and hydrodynamic characteristics that affect the rate of liquid circulation. The models provide a predictive and interpretive capability for the observed axial variation of dissolved oxygen in airlift systems. Use of airlift bioreactors in wastewater treatment is reviewed elsewhere [2].

\section{Theory}

The hydrostatic pressure at any axial position in the riser or the downcomer of an airlift device (Fig. 1) is related to 


\begin{tabular}{|c|c|}
\hline \multicolumn{2}{|c|}{ Nomenclature } \\
\hline$a_{\mathrm{L}}$ & $\begin{array}{l}\text { gas-liquid interfacial area per } \\
\text { unit liquid volume }\left(\mathrm{m}^{-1}\right)\end{array}$ \\
\hline$a_{1}$ & parameter in Eq. (30) \\
\hline$a_{2}$ & parameter in Eq. (31) \\
\hline$A_{\mathrm{b}}$ & cross-sectional area under the baffle $\left(\mathrm{m}^{2}\right)$ \\
\hline$A_{\mathrm{d}}$ & cross-sectional area of downcomer $\left(\mathrm{m}^{2}\right)$ \\
\hline$A_{\mathrm{r}}$ & cross-sectional area of riser $\left(\mathrm{m}^{2}\right)$ \\
\hline$b_{1}$ & parameter in Eq. (30) \\
\hline$b_{2}$ & parameter in Eq. (31) \\
\hline$c_{1}$ & parameter in Eq. (30) \\
\hline$c_{2}$ & parameter in Eq. (31) \\
\hline$C$ & $\begin{array}{l}\text { actual concentration of dissolved } \\
\text { oxygen }\left(\mathrm{kg} \mathrm{m}^{-3}\right)\end{array}$ \\
\hline $\bar{C}$ & $\begin{array}{l}\text { dimensionless concentration of dissolved } \\
\text { oxygen }(-)\end{array}$ \\
\hline$C_{\mathrm{d}}$ & $\begin{array}{l}\text { actual concentration of dissolved oxygen } \\
\text { in downcomer }\left(\mathrm{kg} \mathrm{m}^{-3}\right)\end{array}$ \\
\hline $\bar{C}_{\mathrm{d}}$ & $\begin{array}{l}\text { dimensionless actual concentration of } \\
\text { dissolved oxygen in downcomer }(-)\end{array}$ \\
\hline $\bar{C}_{\mathrm{d}}^{*}$ & $\begin{array}{l}\text { dimensionless saturation concentration of } \\
\text { dissolved oxygen in downcomer }(-)\end{array}$ \\
\hline $\bar{C}_{\mathrm{d}}^{*}(x)$ & $\begin{array}{l}\text { dimensionless saturation concentration of } \\
\text { dissolved oxygen at location } x \\
\text { in downcomer }(-)\end{array}$ \\
\hline$C_{\mathrm{d}}^{*}(z)$ & $\begin{array}{l}\text { saturation concentration of } \\
\text { dissolved oxygen at location } z \text { in } \\
\text { downcomer }\left(\mathrm{kg} \mathrm{m}^{-3}\right)\end{array}$ \\
\hline$C_{\mathrm{r}}$ & $\begin{array}{l}\text { actual concentration of dissolved } \\
\text { oxygen in riser }\left(\mathrm{kg} \mathrm{m}^{-3}\right)\end{array}$ \\
\hline $\bar{C}_{\mathrm{r}}$ & $\begin{array}{l}\text { dimensionless actual concentration of } \\
\text { dissolved oxygen in riser }(-)\end{array}$ \\
\hline $\bar{C}_{\mathrm{r}}^{*}$ & $\begin{array}{l}\text { dimensionless saturation concentration of } \\
\text { dissolved oxygen in riser }(-)\end{array}$ \\
\hline $\bar{C}_{\mathrm{r}}^{*}(x)$ & $\begin{array}{l}\text { dimensionless saturation concentration of } \\
\text { dissolved oxygen at location } x \text { in riser }(-)\end{array}$ \\
\hline$C_{\mathrm{r}}^{*}(z)$ & $\begin{array}{l}\text { saturation concentration of dissolved } \\
\text { oxygen at location } z \text { in riser }\left(\mathrm{kg} \mathrm{m}^{-3}\right)\end{array}$ \\
\hline $\mathrm{ct}_{1-4}$ & constants of integration $(-)$ \\
\hline $\operatorname{cte}_{1-4}$ & constants of integration $(-)$ \\
\hline$D_{z \mathrm{~d}}$ & $\begin{array}{l}\text { axial dispersion coefficient for liquid } \\
\text { in downcomer }\left(\mathrm{m}^{2} \mathrm{~s}^{-1}\right)\end{array}$ \\
\hline$D_{z \mathrm{r}}$ & $\begin{array}{l}\text { axial dispersion coefficient for liquid } \\
\text { in riser }\left(\mathrm{m}^{2} \mathrm{~s}^{-1}\right)\end{array}$ \\
\hline$f_{1-3}$ & parameters defined by Eqs. (36)-(38) \\
\hline$g$ & gravitational acceleration $\left(\mathrm{m} \mathrm{s}^{-2}\right)$ \\
\hline$h_{\mathrm{D}}$ & height of dispersion $(\mathrm{m})$ \\
\hline$h_{\mathrm{L}}$ & height of gas-free liquid (m) \\
\hline$H_{0}$ & Henry's law constant $\left(\mathrm{Pa} \mathrm{kg}^{-1} \mathrm{~m}^{3}\right)$ \\
\hline$k$ & $\begin{array}{l}\text { dimensionless concentration ratio } \\
\text { at } x=1(\text { Model A) }(-)\end{array}$ \\
\hline $\begin{array}{l}k_{\mathrm{L}} \\
k_{1}\end{array}$ & $\begin{array}{l}\text { liquid film mass transfer coefficient }\left(\mathrm{m} \mathrm{s}^{-1}\right) \\
\text { dimensionless concentration ratio } \\
\text { at } x=0(-)\end{array}$ \\
\hline
\end{tabular}

\begin{tabular}{|c|c|}
\hline$k_{2}$ & $\begin{array}{l}\text { dimensionless concentration ratio } \\
\text { at } x=1(-)\end{array}$ \\
\hline$k_{\mathrm{L}} a_{\mathrm{L}}$ & $\begin{array}{l}\text { overall gas-liquid volumetric mass } \\
\text { transfer coefficient }\left(\mathrm{s}^{-1}\right)\end{array}$ \\
\hline$\left(k_{\mathrm{L}} a_{\mathrm{L}}\right)_{\mathrm{d}}$ & $\begin{array}{l}\text { overall gas-liquid volumetric mass } \\
\text { transfer coefficient in downcomer }\left(\mathrm{s}^{-1}\right)\end{array}$ \\
\hline$\left(k_{\mathrm{L}} a_{\mathrm{L}}\right)_{\mathrm{r}}$ & $\begin{array}{l}\text { overall gas-liquid volumetric mass } \\
\text { transfer coefficient in riser }\left(\mathrm{s}^{-1}\right)\end{array}$ \\
\hline$K_{\mathrm{B}}$ & $\begin{array}{l}\text { form frictional loss coefficient for the } \\
\text { bottom zone }(-)\end{array}$ \\
\hline$P_{\mathrm{a}}$ & pressure in reactor headspace $(\mathrm{Pa})$ \\
\hline$P_{\mathrm{b}}$ & $\begin{array}{l}\text { hydrostatic pressure at the bottom of } \\
\text { unaerated vessel }(\mathrm{Pa})\end{array}$ \\
\hline$P_{\mathrm{d}}(z)$ & $\begin{array}{l}\text { hydrostatic pressure at height } z \text { from the } \\
\text { bottom of downcomer }(\mathrm{Pa})\end{array}$ \\
\hline$P_{\mathrm{G}}$ & power input due to gas $(\mathrm{W})$ \\
\hline$P_{\mathrm{r}}(z)$ & $\begin{array}{l}\text { hydrostatic pressure at height } z \text { from } \\
\text { the bottom of riser }(\mathrm{Pa})\end{array}$ \\
\hline$P e_{\mathrm{d}}$ & Peclet number in downcomer (-) \\
\hline$P e_{\mathrm{r}}$ & Peclet number in riser $(-)$ \\
\hline$r_{1-4}$ & characteristic roots $(-)$ \\
\hline$R$ & overall rate of reaction $\left(\mathrm{kg} \mathrm{m}^{3} \mathrm{~s}^{-1}\right)$ \\
\hline$U_{\mathrm{Gr}}$ & superficial gas velocity in riser $\left(\mathrm{m} \mathrm{s}^{-1}\right)$ \\
\hline$U_{\mathrm{Lr}}$ & superficial liquid velocity in riser $\left(\mathrm{m} \mathrm{s}^{-1}\right)$ \\
\hline$V_{\mathrm{L}}$ & volume of liquid $\left(\mathrm{m}^{3}\right)$ \\
\hline$V_{\mathrm{Ld}}$ & $\begin{array}{l}\text { interstitial liquid velocity in } \\
\text { downcomer }\left(\mathrm{m} \mathrm{s}^{-1}\right)\end{array}$ \\
\hline$V_{\mathrm{Lr}}$ & interstitial liquid velocity in riser $\left(\mathrm{m} \mathrm{s}^{-1}\right)$ \\
\hline$w_{1-3}$ & parameters defined by Eqs. (39)-(41) \\
\hline$x$ & dimensionless axial height $(-)$ \\
\hline$x_{\mathrm{d}}$ & $\begin{array}{l}\text { dimensionless axial position at which the } \\
\text { concentration is minimum in downcomer (-) }\end{array}$ \\
\hline$x_{\mathrm{r}}$ & $\begin{array}{l}\text { dimensionless axial position at which the } \\
\text { concentration is maximum in riser }(-)\end{array}$ \\
\hline$y_{0}$ & mole fraction of oxygen in the gas-phase (-) \\
\hline$z$ & axial distance $(\mathrm{m})$ \\
\hline \multicolumn{2}{|c|}{ Greek symbols } \\
\hline$\alpha$ & $\begin{array}{l}\text { dimensionless parameter defined } \\
\text { by Eq. (25) (-) }\end{array}$ \\
\hline$\beta$ & $\begin{array}{l}\text { dimensionless parameter defined } \\
\text { by Eq. (26) (-) }\end{array}$ \\
\hline$\gamma_{\mathrm{d}}$ & parameter defined by Eq. (16) (-) \\
\hline$\gamma_{\mathrm{r}}$ & parameter defined by Eq. (15) (-) \\
\hline$\varepsilon_{\mathrm{G}}$ & overall gas holdup (-) \\
\hline$\varepsilon_{\mathrm{Gd}}$ & downcomer gas holdup (-) \\
\hline$\varepsilon_{\mathrm{Gr}}$ & riser gas holdup $(-)$ \\
\hline$\theta$ & $\begin{array}{l}\text { dimensionless parameter defined } \\
\text { by Eq. }(28)(-)\end{array}$ \\
\hline$\lambda$ & $\begin{array}{l}\text { dimensionless parameter defined } \\
\text { by Eq. (27) (-) }\end{array}$ \\
\hline$\rho_{\mathrm{L}}$ & density of the liquid $\left(\mathrm{kg} \mathrm{m}^{-3}\right)$ \\
\hline$\phi$ & ratio $\varepsilon_{\mathrm{Gd}} / \varepsilon_{\mathrm{Gr}}(-)$ \\
\hline$\psi$ & parameter in Eq. (46) (-) \\
\hline
\end{tabular}



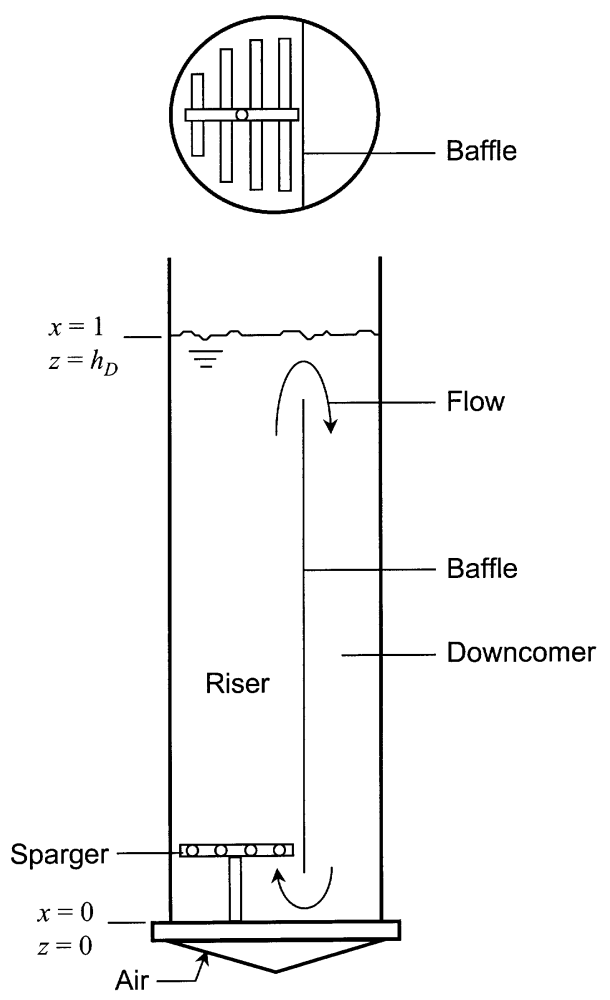

Fig. 1. Schematic diagram of the split-cylinder airlift reactor.

the height $h_{\mathrm{D}}$ of the gas-liquid dispersion, the density of the fluid, and the fractional gas holdup values in the riser and the downcomer. The pressure at any axial location $z$ from the bottom of the vessel can be shown to be

$P_{\mathrm{r}}(z)=P_{\mathrm{a}}+\rho_{\mathrm{L}}\left(1-\varepsilon_{\mathrm{Gr}}\right) g\left(h_{\mathrm{D}}-z\right)$,

$P_{\mathrm{d}}(z)=P_{\mathrm{a}}+\rho_{\mathrm{L}}\left(1-\varepsilon_{\mathrm{Gd}}\right) g\left(h_{\mathrm{D}}-z\right)$

for the riser and the downcomer zones, respectively. In Eqs. (1) and (2), $P_{\mathrm{a}}$ is the pressure in the headspace of the reactor, $g$ the gravitational acceleration, and $\rho_{\mathrm{L}}$ the density of the liquid-phase. $\varepsilon_{\mathrm{Gr}}$ and $\varepsilon_{\mathrm{Gd}}$ are the average fractional gas holdups in the riser and the downcomer zones, respectively. Eqs. (1) and (2) assume axially invariant gas holdup values. In practice, the holdups vary axially $[8,9]$ but the variation is generally much less pronounced in the riser of an airlift vessel [10] than in a typical bubble column. More substantial holdup variations occur in the downcomer where the holdup declines axially downward [5,10]; however, such variations have generally been disregarded in the literature and currently no empirical or analytical correlations are available for local gas holdup. The axial variation in holdup is due to a combination of pressure changes and bubble coalescence and breakup.

Because the solubility of a sparingly soluble gas such as oxygen is governed by Henry's law, the saturation concentration $C^{*}$ of dissolved oxygen at any axial position $z$ is given by the equations

$$
\begin{aligned}
& C_{\mathrm{r}}^{*}(z)=\frac{y_{0} P_{\mathrm{r}}(z)}{H_{0}}=\frac{y_{0} P_{\mathrm{a}}+y_{0} \rho_{\mathrm{L}}\left(1-\varepsilon_{\mathrm{Gr}}\right) g\left(h_{\mathrm{D}}-z\right)}{H_{0}}, \\
& C_{\mathrm{d}}^{*}(z)=\frac{y_{0} P_{\mathrm{d}}(z)}{H_{0}}=\frac{y_{0} P_{\mathrm{a}}+y_{0} \rho_{\mathrm{L}}\left(1-\varepsilon_{\mathrm{Gd}}\right) g\left(h_{\mathrm{D}}-z\right)}{H_{0}}
\end{aligned}
$$

for the riser and the downcomer, respectively. Here $y_{0}$ is the mole fraction of oxygen in the gas-phase and $H_{0}$ the Henry law constant. Eqs. (3) and (4) assume a constant gas-phase composition which is approximately valid [5] at steady-state in the absence of an oxygen consuming reaction, as is the case in this work. Based on theoretical equations (3) and (4), the steady-state dissolved oxygen concentration is a linear function of the axial position both in the riser and the downcomer; the steady-state dissolved oxygen concentration declines as we move up the airlift column. The axial concentration profiles provided by Eqs. (3) and (4) apply to a hypothetical airlift device with zero axial mixing and the absence of liquid circulation. In practice, airlift reactors circulate: the liquid flows up the riser and down the downcomer; in addition, there is a finite amount of axial mixing of liquid in the riser and downcomer zones. Liquid circulation and axial mixing alter the axial concentration profile.

The measured steady-state axial dissolved oxygen profiles in split-cylinder airlift devices [5] have indeed been different from the predictions of Eq. (3). The reported measurements spanned working aspect ratios of up to about 22, the gas-liquid dispersion heights of up to about $5.4 \mathrm{~m}$, and extremes of mixing situations represented by a broad range of gas flow rates [5]. As discussed here, the shape of the profiles can be predicted using mathematical models that consider the hydrodynamic and mass transport phenomena occurring in airlift bioreactors. These approaches allow us to clearly identify the factors that influence the dissolved oxygen profiles and establish the sensitivity of the profiles to the various factors.

Using a horizontal segment of the riser zone as a control volume, an oxygen mass balance can be written as

$D_{z \mathrm{r}} \frac{\mathrm{d}^{2} C_{\mathrm{r}}}{\mathrm{d} z^{2}}-V_{\mathrm{Lr}} \frac{\mathrm{d} C_{\mathrm{r}}}{\mathrm{d} z}+\left(k_{\mathrm{L}} a_{\mathrm{L}}\right)_{\mathrm{r}}\left(C_{\mathrm{r}}^{*}-C_{\mathrm{r}}\right)-R=0$,

where $\mathrm{d} z$ is the segment height. $D_{z \mathrm{r}}$ and $V_{\mathrm{Lr}}$ in Eq. (5) are the axial dispersion coefficient and the interstitial liquid velocity in the riser, respectively. $C_{\mathrm{r}}$ is the dissolved oxygen concentration at position $z$ in the riser, $C_{\mathrm{r}}^{*}$ the theoretical saturation concentration of oxygen at position $z$, and $\left(k_{\mathrm{L}} a_{\mathrm{L}}\right)_{\mathrm{r}}$ the volumetric gas-liquid oxygen transfer coefficient for the riser zone. The first term in Eq. (5) represents the change in the dissolved oxygen concentration in the control volume due to axial dispersion, the second term represents the change in concentration due to convective flow, and the third term accounts for concentration changes due to gas-liquid mass transfer. The volumetric rate of possible oxygen consumption is represented as $R$, but for the purpose of this work $R=0$ and it is disregarded. At steady state, there is no net accumulation or depletion of oxygen in the control volume. 
Using an identical approach for the downcomer and disregarding $R$, we have

$D_{z \mathrm{~d}} \frac{\mathrm{d}^{2} C_{\mathrm{d}}}{\mathrm{d} z^{2}}+V_{\mathrm{Ld}} \frac{\mathrm{d} C_{\mathrm{d}}}{\mathrm{d} z}+\left(k_{\mathrm{L}} a_{\mathrm{L}}\right)_{\mathrm{d}}\left(C_{\mathrm{d}}^{*}-C_{\mathrm{d}}\right)=0$.

The positive sign before $V_{\mathrm{Ld}}$ in Eq. (6) is because the direction of flow in the downcomer is opposite to that of the riser. Eqs. (5) and (6) may be made dimensionless by defining an axial dimensionless height $x$ and a dimensionless dissolved oxygen concentration $\bar{C}$; thus,

$x=\frac{z}{h_{\mathrm{D}}}$,

$\bar{C}=\frac{C}{0.21 P_{\mathrm{b}} / H_{0}}$,

where $P_{\mathrm{b}}$ is the pressure at the bottom of the unaerated column, $P_{\mathrm{b}}=P_{\mathrm{a}}+\rho_{\mathrm{L}} g h_{\mathrm{L}}$. Henceforth, the model development will diverge to accommodate two possible scenarios: (i) a gas-phase that is axially invariant, and (ii) axial change in the gas-phase composition.

\subsection{Model A: constant gas-phase composition}

When the gas-phase composition is axially invariant, i.e., $y_{0}=$ constant, the dimensionless saturation concentrations of oxygen may be written as

$\bar{C}_{\mathrm{r}}^{*}(x)=\frac{P_{\mathrm{r}}(z)}{P_{\mathrm{b}}}=\frac{P_{\mathrm{a}}}{P_{\mathrm{b}}}+\frac{\rho_{\mathrm{L}}\left(1-\varepsilon_{\mathrm{Gr}}\right) g h_{\mathrm{D}}(1-x)}{P_{\mathrm{b}}}$,

$\bar{C}_{\mathrm{d}}^{*}(x)=\frac{P_{\mathrm{d}}(z)}{P_{\mathrm{b}}}=\frac{P_{\mathrm{a}}}{P_{\mathrm{b}}}+\frac{\rho_{\mathrm{L}}\left(1-\varepsilon_{\mathrm{Gd}}\right) g h_{\mathrm{D}}(1-x)}{P_{\mathrm{b}}}$

for the riser and the downcomer, respectively. Based on these definitions, Eqs. (5) and (6) become

$\frac{D_{z \mathrm{r}}}{h_{\mathrm{D}}^{2}} \frac{\mathrm{d}^{2} \bar{C}_{\mathrm{r}}}{\mathrm{d} x^{2}}-\frac{V_{\mathrm{Lr}}}{h_{\mathrm{D}}} \frac{\mathrm{d} \bar{C}_{\mathrm{r}}}{\mathrm{d} x}+\left(k_{\mathrm{L}} a_{\mathrm{L}}\right)_{\mathrm{r}}\left(\bar{C}_{\mathrm{r}}^{*}-\bar{C}_{\mathrm{r}}\right)=0$

$\frac{D_{z \mathrm{~d}}}{h_{\mathrm{D}}^{2}} \frac{\mathrm{d}^{2} \bar{C}_{\mathrm{d}}}{\mathrm{d} x^{2}}+\frac{V_{\mathrm{Ld}}}{h_{\mathrm{D}}} \frac{\mathrm{d} \bar{C}_{\mathrm{d}}}{\mathrm{d} x}+\left(k_{\mathrm{L}} a_{\mathrm{L}}\right)_{\mathrm{d}}\left(\bar{C}_{\mathrm{d}}^{*}-\bar{C}_{\mathrm{d}}\right)=0$.

Using the following additional definitions

$P e_{\mathrm{r}}=\frac{V_{\mathrm{Lr}} h_{\mathrm{D}}}{D_{z \mathrm{r}}}$

$P e_{\mathrm{d}}=\frac{V_{\mathrm{Ld}} h_{\mathrm{D}}}{D_{z \mathrm{~d}}}$,

$\gamma_{\mathrm{r}}=\frac{\left(k_{\mathrm{L}} a_{\mathrm{L}}\right)_{\mathrm{r}} h_{\mathrm{D}}}{V_{\mathrm{Lr}}}$

$\gamma_{\mathrm{d}}=\frac{\left(k_{\mathrm{L}} a_{\mathrm{L}}\right)_{\mathrm{d}} h_{\mathrm{D}}}{V_{\mathrm{Ld}}}$,

Eqs. (11) and (12) are modified to

$\frac{1}{P e_{\mathrm{r}}} \frac{\mathrm{d}^{2} \bar{C}_{\mathrm{r}}}{\mathrm{d} x^{2}}-\frac{\mathrm{d} \bar{C}_{\mathrm{r}}}{\mathrm{d} x}+\gamma_{\mathrm{r}}\left(\bar{C}_{\mathrm{r}}^{*}-\bar{C}_{\mathrm{r}}\right)=0$,
$\frac{1}{P e_{\mathrm{d}}} \frac{\mathrm{d}^{2} \bar{C}_{\mathrm{d}}}{\mathrm{d} x^{2}}+\frac{\mathrm{d} \bar{C}_{\mathrm{d}}}{\mathrm{d} x}+\gamma_{\mathrm{d}}\left(\bar{C}_{\mathrm{d}}^{*}-\bar{C}_{\mathrm{d}}\right)=0$.

Here $P e_{\mathrm{r}}$ and $P e_{\mathrm{d}}$ are the liquid-phase Peclet numbers in the riser and the downcomer zones, respectively.

The general solutions of Eqs. (17) and (18), integrated independently, are

$\bar{C}_{\mathrm{r}}=$ cte $_{1} \mathrm{e}^{r_{1} x}+$ cte $_{2} \mathrm{e}^{r_{2} x}+\alpha-\frac{\beta}{\gamma_{\mathrm{r}}}+\beta x$,

$\bar{C}_{\mathrm{d}}=\operatorname{cte}_{3} \mathrm{e}^{r_{3} x}+\operatorname{cte}_{4} \mathrm{e}^{r_{4} x}+\lambda+\frac{\theta}{\gamma_{\mathrm{d}}}+\theta x$,

respectively. The roots $r_{1-4}$ are as follows:

$r_{1}=\frac{P e_{\mathrm{r}}}{2}\left(1-\sqrt{1+\frac{4 \gamma_{\mathrm{r}}}{P e_{\mathrm{r}}}}\right)$

$r_{2}=\frac{P e_{\mathrm{r}}}{2}\left(1+\sqrt{1+\frac{4 \gamma_{\mathrm{r}}}{P e_{\mathrm{r}}}}\right)$

$r_{3}=\frac{P e_{\mathrm{d}}}{2}\left(-1-\sqrt{1+\frac{4 \gamma_{\mathrm{d}}}{P e_{\mathrm{d}}}}\right)$,

$r_{4}=\frac{P e_{\mathrm{d}}}{2}\left(-1+\sqrt{1+\frac{4 \gamma_{\mathrm{d}}}{P e_{\mathrm{d}}}}\right)$.

The parameters $\alpha, \beta, \lambda$, and $\theta$ in Eqs. (19) and (20) are as follows:

$\alpha=\frac{P_{\mathrm{a}} \rho_{\mathrm{L}}\left(1-\varepsilon_{\mathrm{Gr}}\right) g h_{\mathrm{D}}}{P_{\mathrm{b}}}$,

$\beta=-\frac{\rho_{\mathrm{L}}\left(1-\varepsilon_{\mathrm{Gr}}\right) g h_{\mathrm{D}}}{P_{\mathrm{b}}}$,

$\lambda=\frac{P_{\mathrm{a}}+\rho_{\mathrm{L}}\left(1-\varepsilon_{\mathrm{Gd}}\right) g h_{\mathrm{D}}}{P_{\mathrm{b}}}$,

$\theta=-\frac{\rho_{\mathrm{L}}\left(1-\varepsilon_{\mathrm{Gd}}\right) g h_{\mathrm{D}}}{P_{\mathrm{b}}}$.

The following conditions can be defined for a particular solution:

1. at $x=0, \bar{C}_{\mathrm{r}}=\bar{C}_{\mathrm{d}}$, and $\mathrm{d} \bar{C}_{\mathrm{r}} / \mathrm{d} x=0$ at $x=x_{\mathrm{r}}$ such that $0<x_{\mathrm{r}}<1$

2. at $x=1, \bar{C}_{\mathrm{r}}=k \bar{C}_{\mathrm{d}}$ where $0.9 \leq k \leq 1.0$, and $\mathrm{d} \bar{C}_{\mathrm{d}} / \mathrm{d} x=$ 0 when $x=x_{\mathrm{d}}$ such that $0<x_{\mathrm{d}}<1$.

Here the parameter $k$ is introduced to obtain a slight concentration discontinuity at the top $(x=1)$ and allow for a solution. The parameters $x_{\mathrm{r}}$ and $x_{\mathrm{d}}$ are the axial locations of dissolved oxygen concentration maxima in the riser and the downcomer, respectively. The resulting boundary equations can be expressed in matrix form for simultaneous solution; 
thus,

$$
\begin{gathered}
{\left[\begin{array}{cccc}
1 & 1 & -1 & -1 \\
\mathrm{e}^{r_{1}} & \mathrm{e}^{r_{2}} & -k \mathrm{e}^{r_{3}} & -k \mathrm{e}^{r_{4}} \\
r_{1} \mathrm{e}^{r_{1} x_{\mathrm{r}}} & r_{2} \mathrm{e}^{r_{2} x_{\mathrm{r}}} & 0 & 0 \\
0 & 0 & r_{3} \mathrm{e}^{r_{3} x_{\mathrm{d}}} & r_{4} \mathrm{e}^{r_{4} x_{\mathrm{d}}}
\end{array}\right]\left[\begin{array}{l}
\mathrm{cte}_{1} \\
\text { cte }_{2} \\
\mathrm{cte}_{3} \\
\text { cte }_{4}
\end{array}\right]} \\
=\left[\begin{array}{c}
\lambda+\frac{\theta}{\gamma_{\mathrm{d}}}-\alpha+\frac{\beta}{\gamma_{\mathrm{r}}} \\
k\left(\lambda+\frac{\theta}{\gamma_{\mathrm{d}}}+\theta\right)-\alpha+\frac{\beta}{\gamma_{\mathrm{r}}}-\beta \\
-\beta \\
-\theta
\end{array}\right] .
\end{gathered}
$$

Solution of matrix (29) yields the values of cte 1-4 $_{1-\text { Although }}$ Eqs. (17) and (18) could be integrated analytically as discussed here, solutions have also been confirmed using Mathematica ${ }^{\circledR}$ (Version 2.2, Wolfram Research, IL), a symbolic mathematics software package.

\subsection{Model B: axial variation in gas-phase composition}

At steady state and when there is no consumption of oxygen, the mole fraction of oxygen in the inlet and the exhaust gas streams is necessarily 0.21 ; however, between the inlet and the exhaust points, oxygen may transfer from the gas-phase to the liquid in the lower portion of the column and, for mass balance, a reverse transfer must occur in the upper regions of the column. Thus, a parabolic axial variation in $y_{0}$ is one of the few feasible profiles of gas-phase oxygen. Considering this and Eq. (8), the dimensionless saturation concentrations of oxygen are

$$
\begin{aligned}
\bar{C}_{\mathrm{r}}^{*}(x) & =\frac{y_{0}(x) P_{\mathrm{r}}(x)}{0.21 P_{\mathrm{b}}} \\
& =\frac{y_{0 \mathrm{r}}(x)}{0.21}\left\{\frac{P_{\mathrm{a}}}{P_{\mathrm{b}}}+\frac{\rho_{\mathrm{L}}\left(1-\varepsilon_{\mathrm{Gr}}\right) g h_{\mathrm{D}}(1-x)}{P_{\mathrm{b}}}\right\} \\
& =a_{1}+b_{1} x+c_{1} x^{2}, \\
\bar{C}_{\mathrm{d}}^{*}(x) & =\frac{y_{0}(x) P_{\mathrm{d}}(x)}{0.21 P_{\mathrm{b}}} \\
& =\frac{y_{0 \mathrm{~d}}(x)}{0.21}\left\{\frac{P_{\mathrm{a}}}{P_{\mathrm{b}}}+\frac{\rho_{\mathrm{L}}\left(1-\varepsilon_{\mathrm{Gd}}\right) g h_{\mathrm{D}}(1-x)}{P_{\mathrm{b}}}\right\} \\
& =a_{2}+b_{2} x+c_{2} x^{2}
\end{aligned}
$$

for the riser and the downcomer, respectively. Here $a_{i}, b_{i}$, and $c_{i}$ are arbitrary best-fit constants to define the axial parabolic profile. Using definitions (30) and (31), Eqs. (5) and (6) become

$$
\begin{aligned}
& \frac{1}{P e_{\mathrm{r}}} \frac{\mathrm{d}^{2} \bar{C}_{\mathrm{r}}}{\mathrm{d} x^{2}}-\frac{\mathrm{d} \bar{C}_{\mathrm{r}}}{\mathrm{d} x}+\gamma_{\mathrm{r}}\left(\left(a_{1}+b_{1} x+c_{1} x^{2}\right)-\bar{C}_{\mathrm{r}}\right)=0, \\
& \frac{1}{P e_{\mathrm{d}}} \frac{\mathrm{d}^{2} \bar{C}_{\mathrm{d}}}{\mathrm{d} x^{2}}+\frac{\mathrm{d} \bar{C}_{\mathrm{d}}}{\mathrm{d} x}+\gamma_{\mathrm{d}}\left(\left(a_{2}+b_{2} x+c_{2} x^{2}\right)-\bar{C}_{\mathrm{d}}\right)=0 .
\end{aligned}
$$

Here $P e_{\mathrm{r}}, P e_{\mathrm{d}}, \gamma_{\mathrm{r}}$, and $\gamma_{\mathrm{d}}$ are again defined by Eqs. (13)-(16), respectively.
The general solutions of Eqs. (32) and (33), integrated independently, are

$\bar{C}_{\mathrm{r}}=\mathrm{ct}_{1} \mathrm{e}^{r_{1} x}+\mathrm{ct}_{2} \mathrm{e}^{r_{2} x}+f_{1}+f_{2} x+f_{3} x^{2}$,

$\bar{C}_{\mathrm{d}}=\mathrm{ct}_{3} \mathrm{e}^{r_{3} x}+\mathrm{ct}_{4} \mathrm{e}^{r_{4} x}+w_{1}+w_{2} x+w_{3} x^{2}$,

respectively. The roots $r_{1-4}$ of Eqs. (34) and (35) are identical to those noted earlier (Eqs. (21)-(24)) and the parameters $f_{i}$ and $w_{i}$ are as follows:

$f_{1}=a_{1}+\frac{2 c_{1}}{\gamma_{\mathrm{r}} P e_{\mathrm{r}}}+\frac{-b_{1}+2 c_{1} / \gamma_{\mathrm{r}}}{\gamma_{\mathrm{r}}}$

$f_{2}=b_{1}-\frac{2 c_{1}}{\gamma_{\mathrm{r}}}$,

$f_{3}=c_{1}$,

$w_{1}=a_{2}+\frac{2 c_{2}}{\gamma_{\mathrm{d}} P e_{\mathrm{d}}}-\frac{-b_{2}+2 c_{2} / \gamma_{\mathrm{d}}}{\gamma_{\mathrm{d}}}$

$w_{2}=b_{2}-\frac{2 c_{2}}{\gamma_{\mathrm{d}}}$,

$w_{3}=c_{2}$.

The conditions for a particular solution are

1. at $x=0, \bar{C}_{\mathrm{r}}=k_{1} \bar{C}_{\mathrm{d}}$, and $\mathrm{d} \bar{C}_{\mathrm{r}} / \mathrm{d} x=0$ at $x=x_{\mathrm{r}}$ such that $0<x_{\mathrm{r}}<1$;

2. at $x=1, \bar{C}_{\mathrm{r}}=k_{2} \bar{C}_{\mathrm{d}}$, and $\mathrm{d} \bar{C}_{\mathrm{d}} / \mathrm{d} x=0$ when $x=x_{\mathrm{d}}$ such that $0<x_{\mathrm{d}}<1$. Here $k_{1}$ and $k_{2}$ are introduced to account for possible discontinuities (none in the present case; hence, $k_{1}=k_{2}=1$ ). The resulting boundary equations can be written as a matrix for simultaneous solution; thus,

$$
\begin{gathered}
{\left[\begin{array}{cccc}
1 & 1 & -k_{1} & -k_{1} \\
r_{1} \mathrm{e}^{r_{1} x_{\mathrm{r}}} & r_{2} \mathrm{e}^{r_{2} x_{\mathrm{r}}} & 0 & 0 \\
\mathrm{e}^{r_{1}} & \mathrm{e}^{r_{2}} & -k_{2} \mathrm{e}^{r_{3}} & -k_{2} \mathrm{e}^{r_{4}} \\
0 & 0 & r_{3} \mathrm{e}^{r_{3} x_{\mathrm{d}}} & r_{4} \mathrm{e}^{r_{4} x_{\mathrm{d}}}
\end{array}\right]\left[\begin{array}{c}
\mathrm{ct}_{1} \\
\mathrm{ct}_{2} \\
\mathrm{ct}_{3} \\
\mathrm{ct}_{4}
\end{array}\right]} \\
=\left[\begin{array}{c}
k_{1} w_{1}-f_{1} \\
-f_{2}-2 f_{3} x_{\mathrm{r}} \\
k_{2}\left(w_{1}+w_{2}+w_{3}\right)-\left(f_{1}+f_{2}+f_{3}\right) \\
-w_{2}-2 w_{3} x_{\mathrm{d}}
\end{array}\right] .
\end{gathered}
$$

Solution of matrix (42) provides the values of $\mathrm{ct}_{1-4}$. Again, the analytical solutions of Eqs. (32) and (33) as discussed here were confirmed using the Mathematica ${ }^{\circledR}$ software. Naturally, for otherwise identical conditions, the best-fit $P e_{\mathrm{r}}, P e_{\mathrm{d}}, \gamma_{\mathrm{r}}$, and $\gamma_{\mathrm{d}}$ values for the two models are different.

\section{Measurements}

The split-cylinder airlift reactor used [5] had a gas-free liquid height of $3.45 \mathrm{~m}$ and an overall height of $8.05 \mathrm{~m}$. The vessel diameter was $0.24 \mathrm{~m}$. An aluminum baffle, held in position by several locating pieces, divided the column 
into a riser and a downcomer (Fig. 1). The baffle width was $0.23 \mathrm{~m}$, giving a downcomer-to-riser cross-sectional area ratio of 0.41 . The equivalent hydraulic diameters of the riser and the downcomer channels were 0.19 and $0.10 \mathrm{~m}$, respectively. The baffle clearance from the base of the vessel was $0.10 \mathrm{~m}$ and the height of the baffle was $3.2 \mathrm{~m}$. Potable tap water at $21^{\circ} \mathrm{C}$ was the liquid-phase; it had $325 \mathrm{mg} \mathrm{l}^{-1}$ total dissolved solids and a total hardness of $320 \mathrm{mgl}^{-1}$ [5]. The airlift column was sparged with air in the riser. A perforated pipe ladder type sparger (Fig. 1) was used and it had 38 holes of $1.5 \times 10^{-3} \mathrm{~m}$ diameter [5]. The sparger was located just inside the riser, $0.15 \mathrm{~m}$ above the base of the reactor. The vessel was open to atmosphere and the local atmospheric pressure was $99.5 \mathrm{kPa}$ absolute. The gas was sparged at superficial velocities of $3.7 \times 10^{-2}$ and $9.8 \times 10^{-2} \mathrm{~m} \mathrm{~s}^{-1}$, measured in the riser section.

The steady-state dissolved oxygen concentrations were measured in the riser zone [5]. The concentration data were reproducible to within $\pm 3 \%$. The measurements were automatically corrected for temperature variations which remained within $\pm 2{ }^{\circ} \mathrm{C}$ [5]. The overall volumetric gas-liquid mass transfer coefficient was determined by the dynamic gassing-in method [5]. The overall gas holdup was measured by the volume expansion technique [5]. The holdups in the riser and the downcomer zones were measured manometrically [5].

\section{Results and discussion}

For Model A, Eq. (19) was used to fit the model concentration profile to the measured data in the riser zone; the corresponding concentration profile in the downcomer was computed with Eq. (20). All simulations and parameter determinations employed Matlab ${ }^{\circledR}$ (Version 5.0, The MathWorks, MA) modeling and simulation software package. The model required values of the following variables: the linear liquid velocities in the riser $\left(V_{\mathrm{Lr}}\right)$ and the downcomer $\left(V_{\mathrm{Ld}}\right)$, the overall height $\left(h_{\mathrm{D}}\right)$ of the gas-liquid dispersion, the liquid-phase axial dispersion coefficients in the riser $\left(D_{z \mathrm{r}}\right)$ and the downcomer $\left(D_{z \mathrm{~d}}\right)$, the volumetric gas-liquid mass transfer coefficient for the riser $\left(\left(k_{\mathrm{L}} a_{\mathrm{L}}\right)_{\mathrm{r}}\right)$ and the downcomer $\left(\left(k_{\mathrm{L}} a_{\mathrm{L}}\right)_{\mathrm{d}}\right)$, the parameter $k$, and the location of the concentration turning points, i.e., $x_{\mathrm{r}}$ and $x_{\mathrm{d}}$, in the riser and the downcomer. Of these variables, $D_{z \mathrm{r}}$ was used as a principal fitting parameter with $D_{z \mathrm{~d}}$ being expressed as a constant factor of $D_{z \mathrm{r}}$ at a given aeration rate. The parameter $k$ was varied within the earlier noted restrictive bounds; the unknown $x_{\mathrm{d}}$ was also a fitting parameter within a limited range, i.e., $0 \leq x_{\mathrm{d}} \leq 1$. The other variables were specified based on measured data as detailed below.

The overall oxygen transfer coefficient was calculated with the equation

$k_{\mathrm{L}} a_{\mathrm{L}}=1.27 \times 10^{-4}\left(\frac{P_{\mathrm{G}}}{V_{\mathrm{L}}}\right)^{0.925}$ where the specific power input depended on the superficial gas velocity in the riser zone [5]; thus,

$$
\frac{P_{\mathrm{G}}}{V_{\mathrm{L}}}=\frac{\rho_{\mathrm{L}} g U_{\mathrm{Gr}}}{1+A_{\mathrm{d}} / A_{\mathrm{r}}} .
$$

In Eq. (44), $U_{\mathrm{Gr}}$ is the superficial aeration velocity in the riser section, and $A_{\mathrm{r}}$ and $A_{\mathrm{d}}$ are the cross-sectional areas of the riser and the downcomer, respectively. Eq. (43) was obtained empirically for the airlift device of interest in this work [5]. $\left(k_{\mathrm{L}} a_{\mathrm{L}}\right)_{\mathrm{r}}$ and $\left(k_{\mathrm{L}} a_{\mathrm{L}}\right)_{\mathrm{d}}$ values were selected such that the following two equations were satisfied:

$k_{\mathrm{L}} a_{\mathrm{L}}=\frac{\left(k_{\mathrm{L}} a_{\mathrm{L}}\right)_{\mathrm{r}} A_{\mathrm{r}}+\left(k_{\mathrm{L}} a_{\mathrm{L}}\right)_{\mathrm{d}} A_{\mathrm{d}}}{A_{\mathrm{r}}+A_{\mathrm{d}}}$,

$\left(k_{\mathrm{L}} a_{\mathrm{L}}\right)_{\mathrm{d}}=\psi\left(k_{\mathrm{L}} a_{\mathrm{L}}\right)_{\mathrm{r}}$.

Eq. (45) is based on fundamental principles as discussed elsewhere [5]. The multiplier $\psi$ was fixed at 0.9 . This value was selected in view of the suggestions that $\left(k_{\mathrm{L}} a_{\mathrm{L}}\right)_{\mathrm{d}}$ is generally less than $\left(k_{\mathrm{L}} a_{\mathrm{L}}\right)_{\mathrm{r}}$ because of the lower gas holdup in the downcomer and its more quiescent hydrodynamic environment relative to the riser [2,5]; however, as shown later in this paper, the precise magnitude of the ratio $\left(k_{\mathrm{L}} a_{\mathrm{L}}\right)_{\mathrm{d}} /\left(k_{\mathrm{L}} a_{\mathrm{L}}\right)_{\mathrm{r}}$ had a negligible impact on the spatial distribution of dissolved oxygen and almost any value of $\psi$ could have been selected.

The height of dispersion $h_{\mathrm{D}}$ was calculated from the known height $h_{\mathrm{L}}$ of the gas-free liquid and the overall gas holdup; thus,

$h_{\mathrm{D}}=\frac{h_{\mathrm{L}}}{1-\varepsilon_{\mathrm{G}}}$,

and the overall gas holdup was obtained with the equation

$\varepsilon_{\mathrm{G}}=4.334 \times 10^{-3}\left(\frac{P_{\mathrm{G}}}{V_{\mathrm{L}}}\right)^{0.499}$.

Eq. (47) is a purely physical relationship [5], whereas Eq. (48) was empirically obtained [5] for the same airlift vessel, fluid, and gas flow rate combinations as discussed in this work.

The liquid velocities were calculated using the methodology detailed by Chisti [5]. The following equation was used:

$U_{\mathrm{Lr}}=\left[\frac{2 g h_{\mathrm{D}}\left(\varepsilon_{\mathrm{Gr}}-\varepsilon_{\mathrm{Gd}}\right)}{K_{\mathrm{B}}\left(A_{\mathrm{r}} / A_{\mathrm{d}}\right)^{2}\left(1 /\left(1-\varepsilon_{\mathrm{Gd}}\right)^{2}\right)}\right]^{0.5}$,

where the parameter $K_{\mathrm{B}}$ is the form friction loss coefficient for the bottom zone of the reactor. Eq. (49) was developed for water and other low viscosity Newtonian media by a purely mechanistic approach $[5,11]$ and, since initial publication, it has been repeatedly validated [12-18]. Eq. (49) has been shown to apply also to the specific reactors used in this work $[5,11]$. The parameter $K_{\mathrm{B}}$ could be estimated using the equation

$K_{\mathrm{B}}=11.40\left(\frac{A_{\mathrm{d}}}{A_{\mathrm{b}}}\right)^{0.79}$, 
where $A_{\mathrm{b}}$ is the area available for flow under the baffle [5]. The $A_{\mathrm{d}} / A_{\mathrm{b}}$ range covered by Eq. (50) is $0.2-1.8[5,11]$. For the split-cylinder reactor of interest in this work, $K_{\mathrm{B}}$ value was 22. This value was based on Eq. (50) with a correction for the additional flow restriction due to the positioning of the sparger inside the riser (see Fig. 1). The method for estimating $K_{\mathrm{B}}$ had been proved in earlier unrelated work with the specific reactors used in this study [5,11]. The superficial liquid velocity $\left(U_{\mathrm{Lr}}\right)$ calculated with Eq. (49) could be converted to the interstitial liquid velocity in the riser $\left(V_{\mathrm{Lr}}\right)$ and the corresponding velocity in the downcomer $\left(V_{\mathrm{Ld}}\right)$; thus,

$V_{\mathrm{Lr}}=\frac{U_{\mathrm{Lr}}}{1-\varepsilon_{\mathrm{Gr}}}$

$V_{\mathrm{Lr}}\left(1-\varepsilon_{\mathrm{Gr}}\right) A_{\mathrm{r}}=V_{\mathrm{Ld}}\left(1-\varepsilon_{\mathrm{Gd}}\right) A_{\mathrm{d}}$.

Eqs. (51) and (52) are based on overall mass balances as previously noted [5]. Use of Eqs. (49)-(52) for determining the various liquid velocities requires a knowledge of the fractional gas holdups in the riser and the downcomer zones. These holdups are related to the overall holdup by the analytical relationship [5]

$\varepsilon_{\mathrm{G}}=\frac{A_{\mathrm{r}} \varepsilon_{\mathrm{Gr}}+A_{\mathrm{d}} \varepsilon_{\mathrm{Gd}}}{A_{\mathrm{r}}+A_{\mathrm{d}}}$.

An additional equation is necessary for calculation of $\varepsilon_{\mathrm{Gr}}$ and $\varepsilon_{\mathrm{Gd}}$, and that equation is

$\varepsilon_{\mathrm{Gd}}=0.89 \varepsilon_{\mathrm{Gr}}$.

The empirically obtained Eq. (54) has been previously employed [5] successfully for the same reactor-fluid combination as used in this work. The $U_{\mathrm{Lr}}$ values calculated using Eqs. (47), (48), (53) and (54) in Eq. (49) were 0.06 and $0.10 \mathrm{~m} \mathrm{~s}^{-1}$ for the riser aeration rate values of $3.7 \times 10^{-2}$ and $9.8 \times 10^{-2} \mathrm{~m} \mathrm{~s}^{-1}$, respectively. In comparison, the measured riser liquid velocities were 0.09 and $0.11 \mathrm{~m} \mathrm{~s}^{-1}$, respectively, for the lower and the higher aeration rate values; hence, confirming the previously proven reliability of the liquid velocity prediction approach used.

The model generated steady-state axial concentration profiles (Model A) and the measured data are shown in Fig. 2. The modeled curve for the riser section and the data agree almost exactly. The best-fit value of the liquid-phase axial dispersion coefficient in the riser was $0.111 \mathrm{~m}^{2} \mathrm{~s}^{-1}$; the other parameters were as noted in the caption of the figure. The straight line in Fig. 2 represents the theoretically calculated dimensionless values of the saturation concentration of dissolved oxygen (Eq. (9)) for a constant gas-phase composition (i.e., $y_{0}=0.21$ ) in the riser section. A similar line for the downcomer zone would virtually overlap that for the riser. The data shown in Fig. 2 were for the low aeration rate - a superficial gas velocity of $3.7 \times 10^{-2} \mathrm{~m} \mathrm{~s}^{-1}$ in the riser. Model A provided a similarly good fit - well within $\pm 2 \%$ - for steady-state dissolved oxygen data that were obtained at a much higher gas flow rate $\left(U_{\mathrm{Gr}}=9.8 \times 10^{-2} \mathrm{~m} \mathrm{~s}^{-1}\right)$ that corresponded to a highly

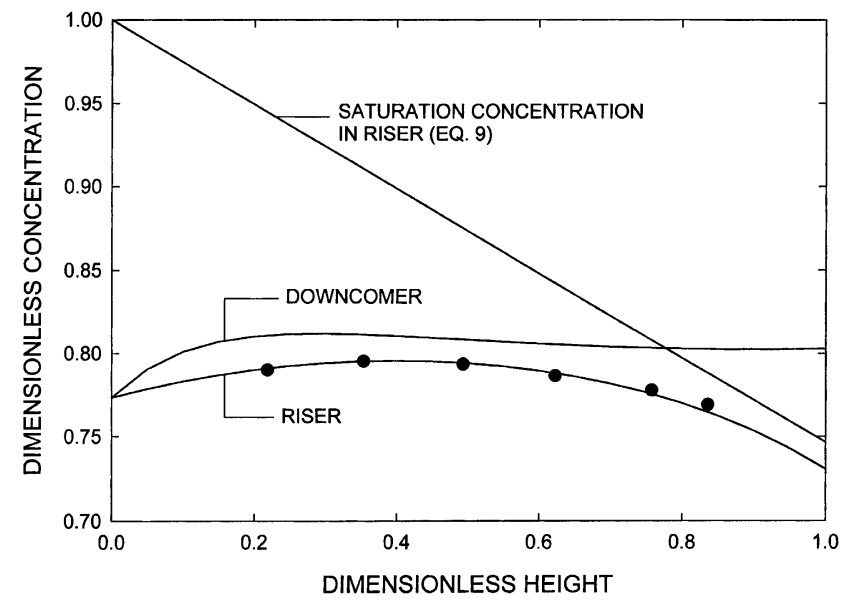

Fig. 2. Axial profiles of dissolved oxygen at steady state in the airlift reactor $\left(U_{\mathrm{Gr}}=3.7 \times 10^{-2} \mathrm{~m} \mathrm{~s}^{-1}\right)$. The straight line represents the saturation concentration of dissolved oxygen (riser) for a constant gas-phase composition $\left(y_{0}=0.21\right)$. The curves are the Model A predictions; the measured data are shown as circles. The model parameters were $k_{\mathrm{L}} a_{\mathrm{L}}=0.022 \mathrm{~s}^{-1}$, $\psi=0.9, U_{\mathrm{Lr}}=0.062 \mathrm{~m} \mathrm{~s}^{-1}, \varepsilon_{\mathrm{G}}=0.069, \varepsilon_{\mathrm{Gr}}=0.071, \varepsilon_{\mathrm{Gd}}=0.063$, $D_{z \mathrm{r}}=0.111 \mathrm{~m}^{2} \mathrm{~s}^{-1}, D_{z \mathrm{~d}}=0.0999 \mathrm{~m}^{2} \mathrm{~s}^{-1}, x_{\mathrm{r}}=0.4, x_{\mathrm{d}}=0.9$, and $k_{2}=0.91$.

turbulent environment. The best-fit value of the $D_{z \mathrm{r}}$ was now $0.17 \mathrm{~m}^{2} \mathrm{~s}^{-1}$, or about $53 \%$ greater than at the lower gas velocity (Fig. 2).

Although the oxygen concentration profiles generated by Model A agreed closely with the measured data in the riser zone, there were two significant problems. The fit always required a concentration discontinuity at the top of the reactor (Fig. 2). Moreover, at the top $(x=1)$, the concentration in the downcomer had to exceed that in the riser zone. The discontinuity was introduced artificially through the parameter $k$ to allow for simultaneous solution of the set of model equations. The magnitude of the discontinuity was quite small for practical purposes: the parameter $k$ varied within extremely restrictive bounds, i.e., $0.9 \leq k \leq 1.0$. The maximum difference in concentrations between the riser and the downcomer at the top of the reactor did not exceed 9\%; nevertheless, in practice, in an airlift reactor such as the one in Fig. 1, no discontinuity is expected in the concentration profiles at the bottom $(x=0)$ and the top $(x=1)$ of the vessel where the fluid reverses direction of flow. Also, $C_{\mathrm{d}}>$ $C_{\mathrm{r}}$ is not generally expected as in Fig. 2. Secondly, the values of the liquid-phase axial dispersion coefficients needed to achieve the fit (Fig. 2) were much greater than expected for similar reactors [19].

These problems were overcome in Model B that accounted for axial variations in the oxygen content of the gas-phase. Now Eq. (34) was used to fit the model concentration profile to the measured data in the riser zone; the corresponding concentration profile in the downcomer was computed with Eq. (35). The model parameters were $a_{1}, b_{1}, c_{1}, a_{2}, b_{2}, c_{2}, P e_{\mathrm{r}}, P e_{\mathrm{d}}, \gamma_{\mathrm{r}}$, and $\gamma_{\mathrm{d}}$. The variables $V_{\mathrm{Lr}}, V_{\mathrm{Ld}}, h_{\mathrm{D}},\left(k_{\mathrm{L}} a_{\mathrm{L}}\right)_{\mathrm{r}}$, and $\left(k_{\mathrm{L}} a_{\mathrm{L}}\right)_{\mathrm{d}}$ were determined using 


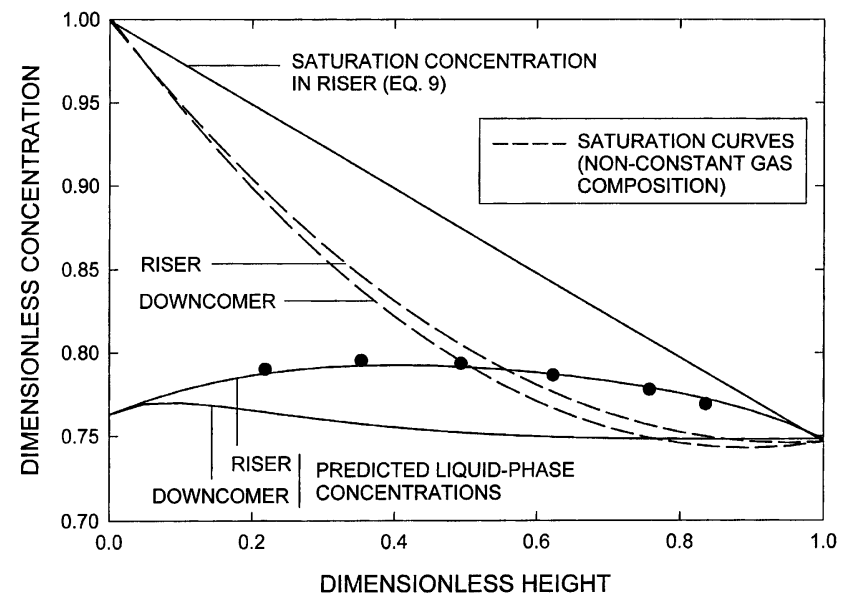

Fig. 3. Axial profiles of dissolved oxygen at steady state in the airlift reactor $\left(U_{\mathrm{Gr}}=3.7 \times 10^{-2} \mathrm{~m} \mathrm{~s}^{-1}\right)$. Also shown are the dissolved oxygen equilibrium concentration (saturation) curves for axially varying $y_{0}$. The solid curves are the model predictions; the data are shown as circles. The model parameters were as in Fig. 2, except $D_{z \mathrm{r}}=0.045 \mathrm{~m}^{2} \mathrm{~s}^{-1}$, $D_{z \mathrm{~d}}=0.040 \mathrm{~m}^{2} \mathrm{~s}^{-1}, x_{\mathrm{d}}=0.85, a_{1}=1, b_{1}=-0.53, c_{1}=-1.1, a_{2}=1$, $b_{2}=-0.58$, and $c_{2}=-4.4 \times 10^{-5}$.

measured data exactly as explained above for Model A. Because now there were no discontinuities in concentration profiles, $k_{1}$ and $k_{2}$ were identical at unity. The measured data set allowed for locating the concentration peak or $x_{\mathrm{r}}$ in the riser. The location $x_{\mathrm{d}}$ of the peak in the downcomer was a fitting parameter within a limited range, i.e., $0 \leq x_{\mathrm{d}} \leq 1$.

As shown in Figs. 3 and 4, respectively, for the low and high aeration rates, the best-fit concentration profiles generated by Model B agreed with the measured data exceedingly well. In Figs. 3 and 4, the straight lines are the theoretically calculated (Eq. (9)) dimensionless saturation concentration profiles for steady-state constant gas-phase composition in

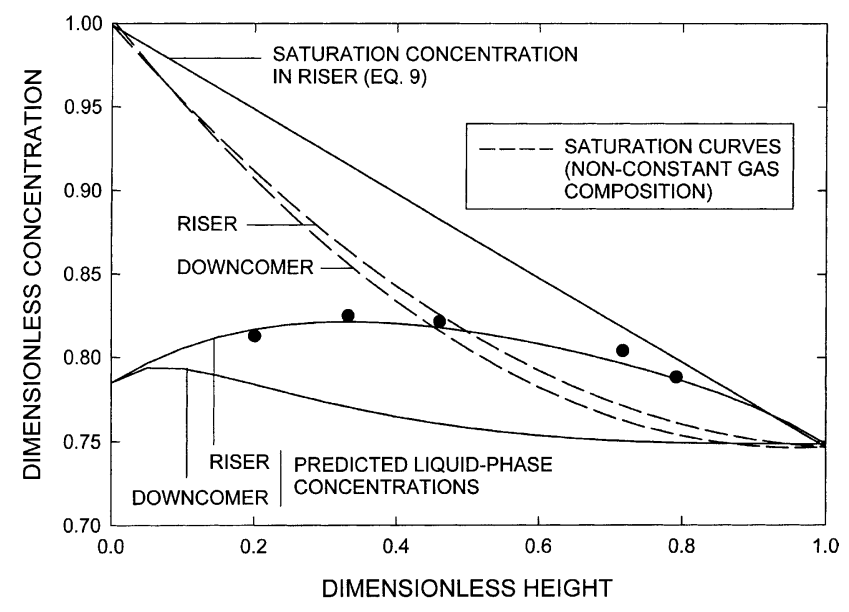

Fig. 4. Axial profiles of dissolved oxygen at steady state in the airlift reactor $\left(U_{\mathrm{Gr}}=9.8 \times 10^{-2} \mathrm{~m} \mathrm{~s}^{-1}\right)$. The solid curves are the model predictions. The model parameters were $k_{\mathrm{L}} a_{\mathrm{L}}=0.053 \mathrm{~s}^{-1}$, $\psi=0.9, U_{\mathrm{Lr}}=0.101 \mathrm{~m} \mathrm{~s}^{-1}, \varepsilon_{\mathrm{G}}=0.112, \varepsilon_{\mathrm{Gr}}=0.116, \varepsilon_{\mathrm{Gd}}=0.103$, $D_{z \mathrm{r}}=0.075 \mathrm{~m}^{2} \mathrm{~s}^{-1}, D_{z \mathrm{~d}}=0.053 \mathrm{~m}^{2} \mathrm{~s}^{-1}, x_{\mathrm{r}}=0.33, x_{\mathrm{d}}=0.95, a_{1}=1$, $b_{1}=-0.48, c_{1}=-0.5, a_{2}=1, b_{2}=-0.53$, and $c_{2}=-1 \times 10^{-4}$.
Table 1

Peclet numbers (Model B) in the riser and the downcomer zones

\begin{tabular}{lll}
\hline Riser gas velocity $\left(\mathrm{m} \mathrm{s}^{-1}\right)$ & $P e_{\mathrm{r}}$ & $P e_{\mathrm{d}}$ \\
\hline 0.04 & 5.5 & 14.8 \\
0.10 & 4.5 & 15.6 \\
\hline
\end{tabular}

the riser zone. The dashed curves are the same steady-state profiles when the gas composition varies with axial position.

Unlike the case with Model A, the best-fit axial dispersion coefficient values were now substantially reduced to levels that were consistent with those reported for tall bubble columns [19]. The best-fit $D_{z \mathrm{r}}$ values were 0.045 and $0.075 \mathrm{~m}^{2} \mathrm{~s}^{-1}$, respectively, for the high and the low aeration rates. The corresponding Peclet numbers in the riser and the downcomer zones are shown in Table 1 for the two aeration rates used. The Peclet numbers were calculated from the best estimates of the axial dispersions coefficients, the linear liquid velocities estimated using the earlier noted procedure, and the height of the gas-liquid dispersion (Eqs. (47) and (48)). The Peclet number values in Table 1 are somewhat low, suggesting that the computed dispersion coefficients, although consistent with those in bubble columns, are still high for an airlift device. Earlier measurements in concentric-tube internal-loop vessels and in external-loop airlift devices have yielded $P e_{\mathrm{r}}$ values of 20-30 in the riser zone, and $P e_{\mathrm{d}}>40$ in the downcomer channel $[2,5,20,21]$. No previous measurements of Peclet numbers are available for split-cylinder airlift vessels, but these devices are expected to behave the same as the others until it is realized that the small but finite gaps between the splitting baffle and the column walls allow significant interchange of fluid between the riser and the downcomer sections. The slight but inevitable movement of the baffle under highly turbulent conditions further accentuates the fluid interchange which is easily observed. Because of this interchange - something that does not occur in conventional concentric-tube and external-loop airlift reactors - the apparent axial dispersion coefficients in the riser and the downcomer are greater than if no leakage were to take place. Consequently, the Peclet number values are reduced by a factor of about 4 in comparison with other kinds of airlift reactors. Lower Peclet numbers signify better axial mixing. Similarly, improved mixing has been reported when the draft-tubes in concentric-tube airlift vessels were replaced with perforated ones $[2,22,23]$.

The flow in the riser of an airlift reactor is comparable to concurrent gas-liquid flow in a vertical pipe [8]. In such two-phase flows, axial dispersion coefficient generally increases with increasing superficial gas velocity. This is consistent with the behavior of the model-estimated dispersion coefficients in this work. In other instances, a more complex relationship between axial dispersion coefficient and the gas flow rate may exist. Thus, for any fixed value of gas flow rate, increases in the concurrent liquid flow velocity are known to produce a decline in the value of axial dispersion coefficient [24]. This is because, for a fixed gas flow rate, increasing 

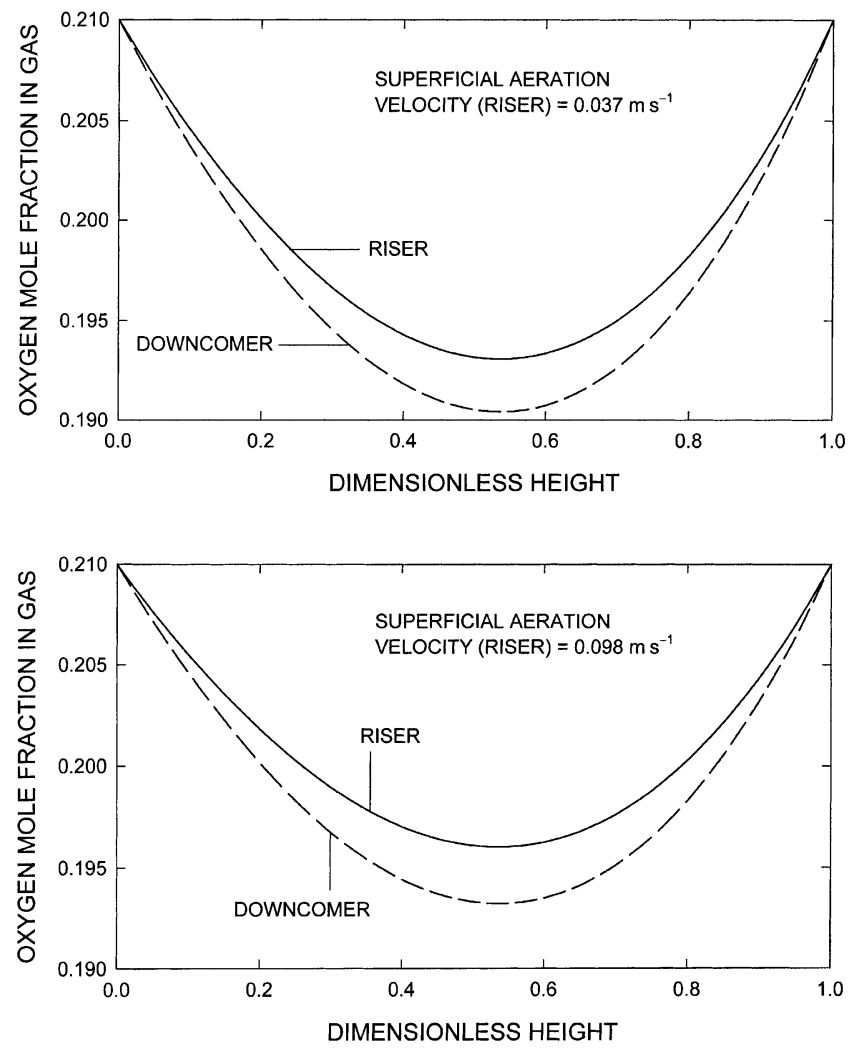

Fig. 5. Axial variations in oxygen in the gas-phase at low and high aeration velocities. Predicted profiles (Eqs. (55) and (56)) are shown for the riser and the downcomer. Only the riser zone is aerated. The gas in the downcomer is entrained from the top of the riser.

liquid velocity reduces the relative velocity between the two phases. In airlift reactors, the gas and liquid velocities are interdependent and the precise nature of this complex, geometry-dependent relationship determines how the dispersion coefficient varies with the superficial gas velocity.

The calculated steady-state axial variation in the gas-phase composition is shown in Fig. 5 for the riser and the downcomer zones at the two values of the aeration rates used. The profiles in the figure were computed using the equations

$$
\begin{aligned}
& y_{0 \mathrm{r}}(x)=\frac{0.21 P_{\mathrm{b}}\left(a_{1}+b_{1} x+c_{1} x^{2}\right)}{P_{\mathrm{a}}+\rho_{\mathrm{L}}\left(1-\varepsilon_{\mathrm{Gr}}\right) g h_{\mathrm{D}}(1-x)}, \\
& y_{0 \mathrm{~d}}(x)=\frac{0.21 P_{\mathrm{b}}\left(a_{2}+b_{2} x+c_{2} x^{2}\right)}{P_{\mathrm{a}}+\rho_{\mathrm{L}}\left(1-\varepsilon_{\mathrm{Gd}}\right) g h_{\mathrm{D}}(1-x)}
\end{aligned}
$$

for the riser and the downcomer, respectively. The parameter values in these equations were selected to attain a best-fit of the modeled liquid-phase oxygen concentration profiles with the measured data. The parameter values were $a_{1}=1$, $b_{1}=-0.53, c_{1}=0.28, a_{2}=1, b_{2}=-0.58$, and $c_{2}=0.32$ when the aeration velocity was $3.7 \times 10^{-2} \mathrm{~m} \mathrm{~s}^{-1}$. For the higher aeration velocity of $9.8 \times 10^{-2} \mathrm{~m} \mathrm{~s}^{-1}$, the parameter values were $a_{1}=1, b_{1}=-0.48, c_{1}=-0.5, a_{2}=1, b_{2}=$ -0.53 , and $c_{2}=0.28$. As shown in Fig. 5, the maximum axial variation in the gas-phase mole fraction of oxygen did not exceed $10 \%$. The variations were always $1-2 \%$ greater in the downcomer relative to those in the riser. The extent of axial variation depended on the aeration rate: the variations were stronger at the lower aeration rate. Note that the mole fraction of oxygen in the inlet and the exhaust gas was always 0.21 (Fig. 5).

Axial variation in the gas-phase composition even at steady state and in the absence of net oxygen transfer is logical and it improves the agreement between the modeled profiles and the data. At the same time, the agreement is achieved for more realistic values of the liquid-phase axial dispersion coefficients than would be possible if the gas-phase was taken to have an axially non-varying composition. Nevertheless, in view of the small maximum change in the gas-phase composition $(<10 \%)$ and the fact that accounting for this change requires additional arbitrary parameters $a_{i}, b_{i}$, and $c_{i}$, the simpler Model A remains a sensible approximation.

In Figs. 3 and 4, the actual axial variation in dissolved oxygen is far less than expected from Henry's law (i.e., straight lines in Figs. 3 and 4). Similar results have been reported for an aqueous slurry of cellulose fibers in a taller airlift vessel [5]. The differences between the straight lines and the experimental data in the figures are due to axial variation in the gas-phase composition, liquid-phase axial mixing, and the circulatory flow. The curves generated by the developed models, which account for the axial mixing and circulation, match the data almost exactly (Figs. 2-4). Based on theoretical reasoning, but no experimental data, Ho et al. [25] also predicted fairly flat axial profiles of dissolved oxygen in tall airlift reactors.

Another aspect that is of particular relevance to wastewater treatment bioreactor design and operation is the sensitivity of the steady-state dissolved oxygen profiles to variations in the gas flow rate, the gas holdup, the $k_{\mathrm{L}} a_{\mathrm{L}}$, the liquid circulation velocity, and the axial liquid-phase dispersion coefficient. A comparison of Figs. 3 and 4 shows that increasing superficial gas velocity $\left(U_{\mathrm{Gr}}\right)$ in the riser enhances the dimensionless steady-state oxygen concentration at any axial position because of improved mass transfer; moreover, the position of the peak in the profile moves to a lower location in the riser zone as the $U_{\mathrm{Gr}}$ is increased. The axial inhomogeneities in dissolved oxygen are more pronounced at the higher aeration rate: changes in aeration rate principally affect the parameter $\gamma_{\mathrm{r}}$, or the relative contributions of gas-liquid mass transfer and the liquid flow (Eq. (15)). Note that the Peclet numbers are not particularly sensitive to the value of $U_{\mathrm{Gr}}$ (Table 1); however, $\gamma_{\mathrm{r}}$ increases from a value of 1.2 to 2.4 as the aeration velocity increases from 0.04 to $0.10 \mathrm{~m} \mathrm{~s}^{-1}$. Changes in $U_{\mathrm{Gr}}$ affect the concentration profile solely by influencing the mass transfer coefficient, the axial dispersion coefficient, the liquid circulation velocity, and the overall gas holdup.

As shown in Fig. 6, small variations in the overall $k_{\mathrm{L}} a_{\mathrm{L}}$, variations of the order of $\pm 15 \%$ in Eq. (43), have little 


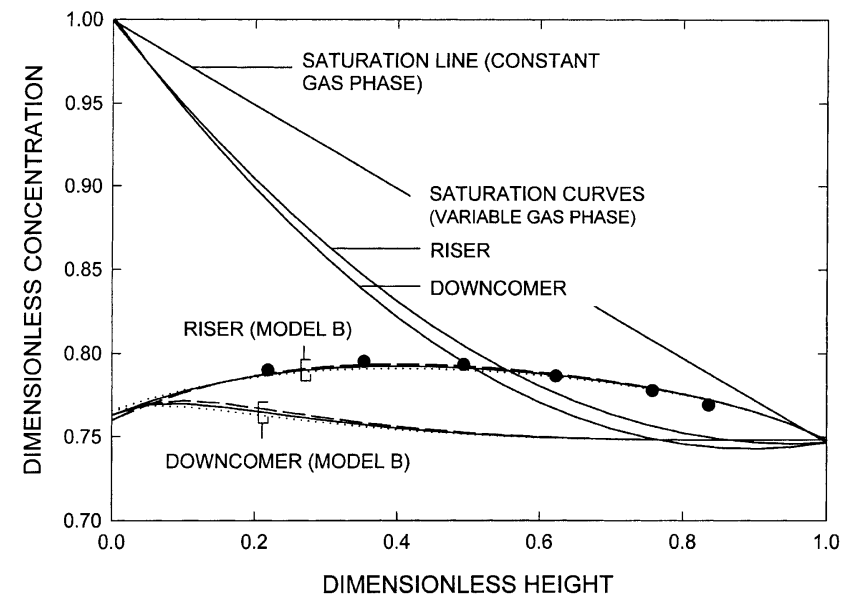

Fig. 6. Axial profiles of dissolved oxygen at steady state in the airlift reactor $\left(U_{\mathrm{Gr}}=3.7 \times 10^{-2} \mathrm{~m} \mathrm{~s}^{-1}\right)$. The model-predicted solid curves are for the same parameter values as in Fig. 3. The dashed model-predicted curves are for a $15 \%$ higher $k_{\mathrm{L}} a_{\mathrm{L}}$. The dotted model-based curves are for a $-15 \%$ change in $k_{\mathrm{L}} a_{\mathrm{L}}$ relative to the best-fit solid curves (i.e., $\left.k_{\mathrm{L}} a_{\mathrm{L}}=0.022 \mathrm{~s}^{-1}\right)$.

impact on the shape or position of the modeled concentration profile. Although the profiles are not substantially affected, the trends of the changes are consistently logical: the dissolved oxygen concentration increases both in the riser and the downcomer as the overall $k_{\mathrm{L}} a_{\mathrm{L}}$ increases. Comparing the simulated curves in Figs. 6 and 7, the oxygen concentration profiles are even less affected by large changes in the relative contributions of the riser and the downcomer zones to the value of the overall $k_{\mathrm{L}} a_{\mathrm{L}}$ (Fig. 7). Thus, whether the $k_{\mathrm{L}} a_{\mathrm{L}}$ in the downcomer is equal to that in the riser, or only $50 \%$ of that in the riser, has virtually no impact on

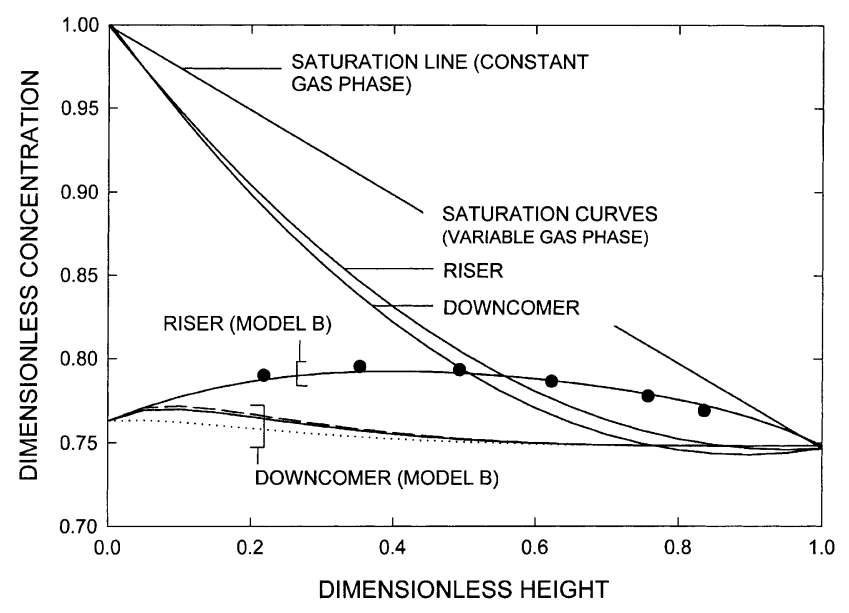

Fig. 7. Axial profiles of dissolved oxygen at steady state in the airlift reactor $\left(U_{\mathrm{Gr}}=3.7 \times 10^{-2} \mathrm{~m} \mathrm{~s}^{-1}\right)$. The two model-based profiles (solid curves) are for the same parameters as in Fig. 3. The dashed and dotted model-based curves are for $\psi$ values of 1.0 and 0.5 , respectively, with all other parameters remaining unchanged. The dashed and dotted profiles in the riser are virtually indistinguishable from the solid curve. The average standard deviation values for the modeled curves were $3.135 \times 10^{-5}$ $(\psi=0.5)$ and $3.133 \times 10^{-5}(\psi=1.0)$.

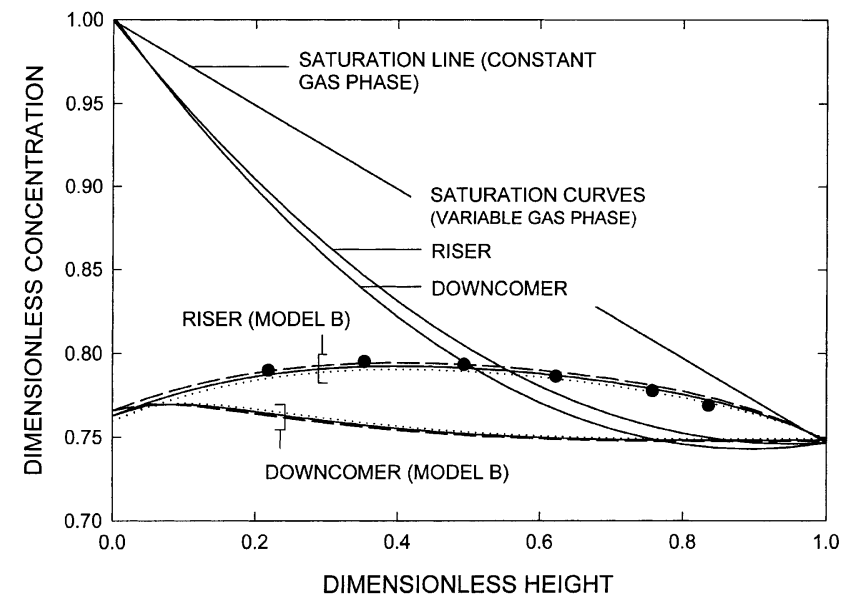

Fig. 8. Axial profiles of dissolved oxygen at steady state in the airlift reactor $\left(U_{\mathrm{Gr}}=3.7 \times 10^{-2} \mathrm{~m} \mathrm{~s}^{-1}\right)$. The model-derived solid curves are for the same parameter values as in Fig. 3 . A $\pm 15 \%$ change in the overall gas holdup affects the predicted concentration profiles as shown. The dashed and the dotted profiles (model curves) are for the higher and lower overall gas holdup values, respectively.

the dissolved oxygen profile (Fig. 7). The observed shifts in profiles are again sensible: reducing $\psi$ from 1.0 to 0.5 produces a decline in the dissolved oxygen concentration in the downcomer because of reduced mass transfer, but the concentration in the riser increases (Fig. 7) because of its increased relative contribution to gas-liquid mass transfer in the reactor.

A $\pm 15 \%$ variation in the overall gas holdup has virtually no effect on the dissolved oxygen profiles (Fig. 8). The noted level of variation in holdup is well above the maximum error in Eq. (48); an error of $\pm 10 \%$ being more typical. Although small changes in the overall gas holdup have little impact, the concentration profiles are quite sensitive to the ratio between the riser and the downcomer gas holdup values (Fig. 9). That ratio greatly affects the water circulation velocity (Eq. (49)); hence, its impact on the concentration profiles. This point is confirmed by the similarities between Figs. 9 and 10. In Fig. 10, the ratio $\varepsilon_{\mathrm{Gd}} / \varepsilon_{\mathrm{Gr}}$ remains unchanged, but the value of the $U_{\mathrm{Lr}}$ is varied from a low of $0.03 \mathrm{~m} \mathrm{~s}^{-1}$ to a high of $0.12 \mathrm{~m} \mathrm{~s}^{-1}$. The range of variation in $\varepsilon_{\mathrm{Gd}} / \varepsilon_{\mathrm{Gr}}$ in Fig. 9 is quite narrow, only about $16 \%$. In contrast, the $U_{\mathrm{Lr}}$ variation in Fig. 10 is fourfold. Clearly, therefore, the concentration profiles are exceedingly sensitive to the $\varepsilon_{\mathrm{Gd}} / \varepsilon_{\mathrm{Gr}}$ ratio. Because the induced liquid circulation rate is influenced by several geometric factors, e.g., $h_{\mathrm{D}}, A_{\mathrm{r}}, A_{\mathrm{d}}$, $A_{\mathrm{b}}$ (Eqs. (49) and (50)), all those parameters will affect the dissolved oxygen profile, specifically by affecting $P e_{\mathrm{r}}, P e_{\mathrm{d}}$, $\gamma_{\mathrm{r}}$, and $\gamma_{\mathrm{d}}$ in Eqs. (19), (20), (34) and (35).

In the specific split-cylinder airlift device used in this work, a value of 0.89 was recommended for the ratio $\varepsilon_{\mathrm{Gd}} / \varepsilon_{\mathrm{Gr}}$ [5]; other similarly high values are the norm for the internal-loop type of airlift vessels that do not have a gas-liquid separator in the head region $[2,5,26]$. When the airlift vessel has a gas-liquid separator, the $\varepsilon_{\mathrm{Gd}} / \varepsilon_{\mathrm{Gr}}$ 


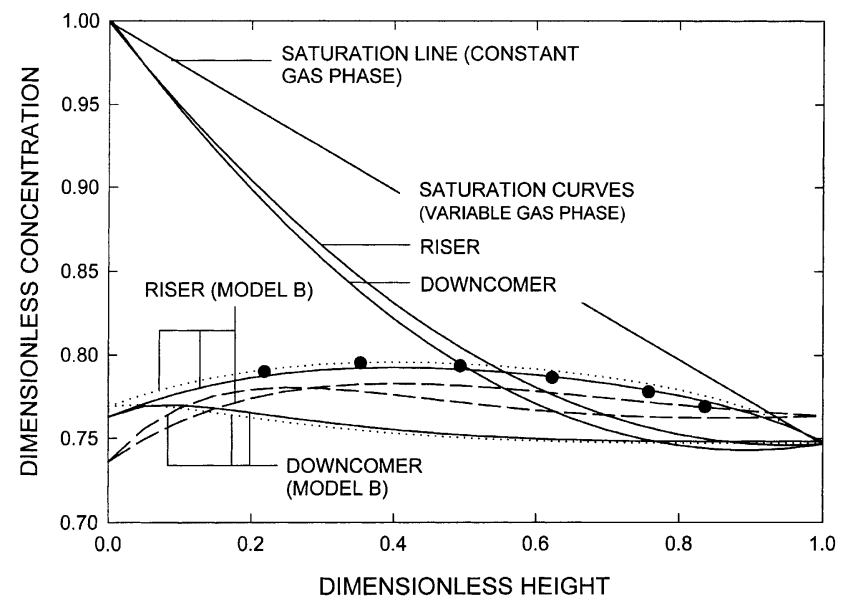

Fig. 9. Axial profiles of dissolved oxygen at steady state in the airlift reactor $\left(U_{\mathrm{Gr}}=3.7 \times 10^{-2} \mathrm{~m} \mathrm{~s}^{-1}\right)$. The model-predicted solid curves are for the same parameter values as in Fig. 3. The dashed and dotted modeled curves are for $\phi$ values of 0.85 and 0.99 in the equation $\varepsilon_{\mathrm{Gd}}=\phi \varepsilon_{\mathrm{Gr}}$. The $\phi$ value for the solid curves is 0.89 . The average standard deviation values for the modeled curves were $8.534 \times 10^{-5}(\phi=0.85)$ and $6.31 \times 10^{-4}$ $(\phi=0.99)$.

value depends on the effectiveness of the separator. A well-designed separator [27] can assure a gas-free downcomer, i.e., $\varepsilon_{\mathrm{Gd}}=0$. In this situation, the methodology described for determining the axial dissolved oxygen profile can still be used: Now $\varepsilon_{\mathrm{Gd}}=0$ in Eqs. (49), (52) and (53); there is no mass transfer in the downcomer, i.e., $\left(k_{\mathrm{L}} a_{\mathrm{L}}\right)_{\mathrm{d}}=0$, and $\gamma_{\mathrm{d}}=0$ in Eq. (18); thus, $\bar{C}_{\mathrm{d}}$ is constant independent of the axial position in the downcomer.

The axial concentration profiles are sensitive to $\pm 40 \%$ change in the absolute value of the dispersion coefficient in the riser (Fig. 11). As expected, within the noted range, a

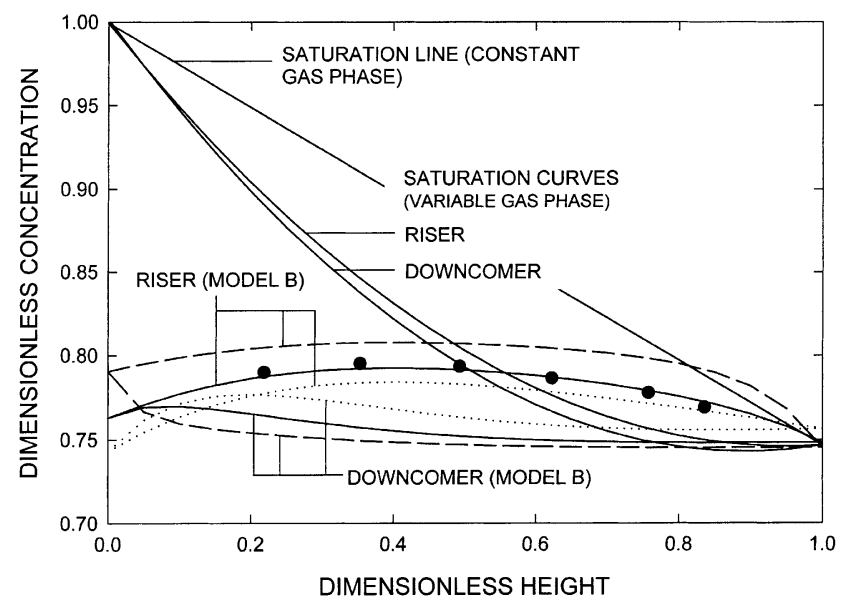

Fig. 10. Axial profiles of dissolved oxygen at steady state in the airlift reactor $\left(U_{\mathrm{Gr}}=3.7 \times 10^{-2} \mathrm{~m} \mathrm{~s}^{-1}\right)$. The model-predicted solid curves are for the same parameter values as in Fig. 3. The dashed and dotted modeled curves are predicted profiles for $U_{\mathrm{Lr}}$ values of 0.124 and $0.031 \mathrm{~m} \mathrm{~s}^{-1}$, respectively. The average standard deviation values for the modeled curves were $5.109 \times 10^{-5}\left(U_{\mathrm{Lr}}=0.031 \mathrm{~m} \mathrm{~s}^{-1}\right)$ and $1.8 \times 10^{-3}$ $\left(U_{\mathrm{Lr}}=0.124 \mathrm{~m} \mathrm{~s}^{-1}\right)$.

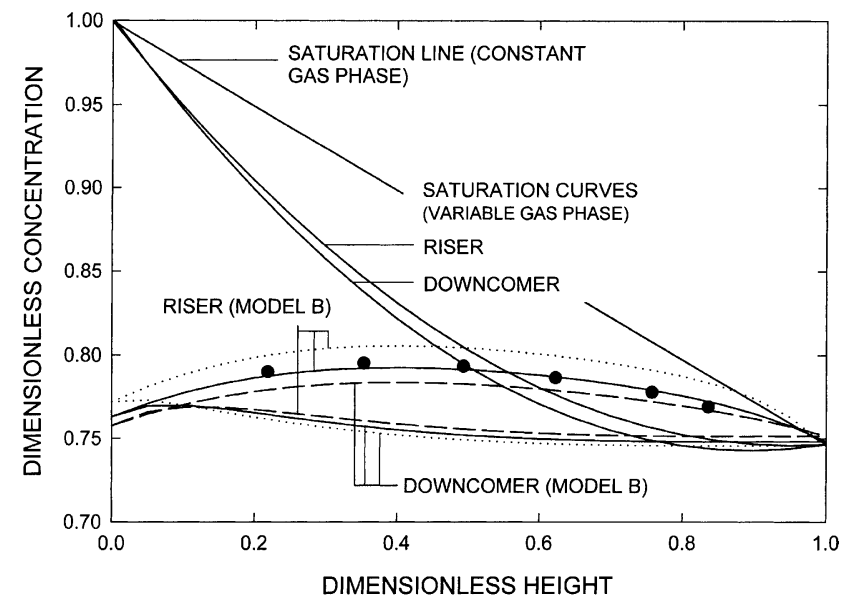

Fig. 11. Axial profiles of dissolved oxygen at steady state in the airlift reactor $\left(U_{\mathrm{Gr}}=3.7 \times 10^{-2} \mathrm{~m} \mathrm{~s}^{-1}\right)$. The model-predicted solid curves are for the same parameter values as in Fig. 3. The other model-predicted profiles are for $40 \%$ higher $D_{z \mathrm{r}}$ (dashed) and $40 \%$ lower $D_{z \mathrm{r}}$ (dotted) relative to the best-fit solid curves. The $D_{z \mathrm{~d}}$ is $0.9 D_{z \mathrm{r}}$ in all cases. The average standard deviation values for the modeled curves were $4.692 \times 10^{-4}(40 \%$ higher $\left.D_{z \mathrm{r}}\right)$ and $8.69 \times 10^{-4}(-40 \%)$.

higher value of $D_{z \mathrm{r}}$ flattens the concentration profile, i.e., the axial variation in oxygen concentration declines over most of the height of the column. A lower value of $D_{z \mathrm{r}}$ leads to a greater spatial inhomogeneity in the level of dissolved oxygen (Fig. 11). Similar effects are seen for the downcomer profiles (Fig. 11). In Fig. 12, at a fixed $D_{z \mathrm{r}}$ value, a substantial $\pm 60 \%$ change in the downcomer dispersion coefficient $\left(D_{z \mathrm{~d}}\right)$ value has little effect on the concentration profiles in the riser zone. In particular, the noted level of variation in $D_{z \mathrm{~d}}$ shifts the riser concentration profile somewhat, but the shape of the profile remains virtually unaltered. In contrast,

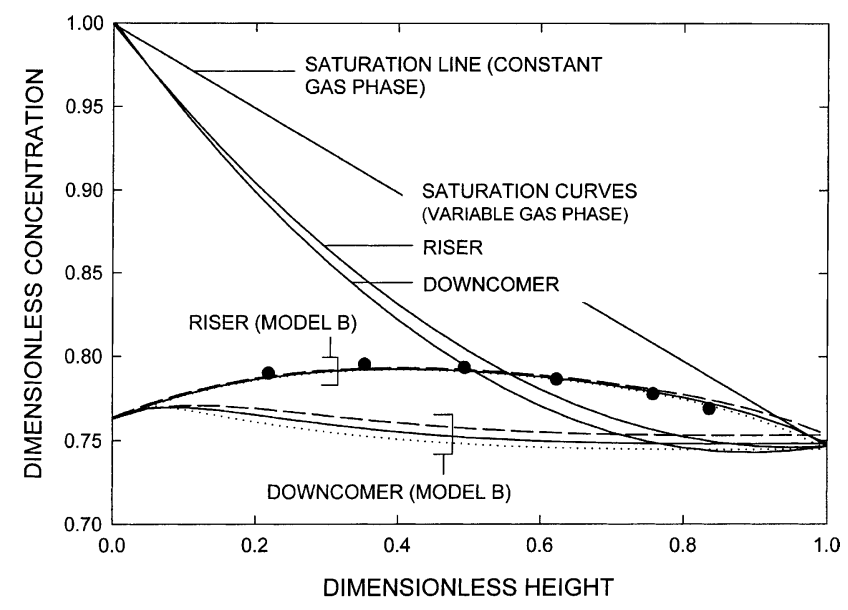

Fig. 12. Axial profiles of dissolved oxygen at steady state in the airlift reactor $\left(U_{\mathrm{Gr}}=3.7 \times 10^{-2} \mathrm{~m} \mathrm{~s}^{-1}\right)$. The model-predicted solid curves are for the same parameter values as in Fig. 3. The other model-predicted profiles are for $60 \%$ higher $D_{z \mathrm{~d}}$ (dashed) and $60 \%$ lower $D_{z \mathrm{~d}}$ (dotted) values relative to the best-fit solid curves. The $D_{z \mathrm{r}}$ is constant at $0.045 \mathrm{~m}^{2} \mathrm{~s}^{-1}$ in all cases. 


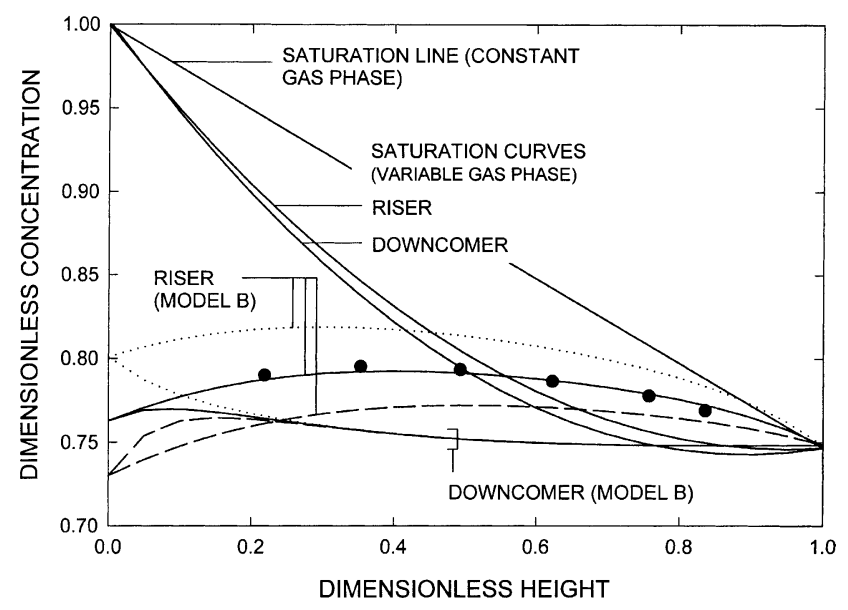

Fig. 13. Axial profiles of dissolved oxygen at steady state in the airlift reactor $\left(U_{\mathrm{Gr}}=3.7 \times 10^{-2} \mathrm{~m} \mathrm{~s}^{-1}\right)$. The model-predicted curves are for $x_{\mathrm{r}}$ values of 0.3 (dotted), 0.4 (solid), and 0.5 (dashed). All other parameters are as in Fig. 3. The average standard deviation values for the modeled curves were $2.5 \times 10^{-3}(x=0.3)$ and $2.4 \times 10^{-3}(x=0.5)$.

the downcomer concentration profile is sensitive to changes in $D_{z \mathrm{~d}}$ (Fig. 12) and the observed variations are sensible, i.e., flatter profiles are seen at higher $D_{z \mathrm{~d}}$ values.

The model-predicted concentration profiles were sensitive also to the values of $x_{\mathrm{r}}$ and $x_{\mathrm{d}}$, i.e., the axial locations of the concentration peaks (or troughs) in the riser and the downcomer sections as shown in Figs. 13 and 14. The best-fit $x_{\mathrm{r}}$ value could be identified from the data set, but $x_{\mathrm{d}}$ was a fitting parameter. Based on the best-fit values of $x_{\mathrm{r}}$ and $x_{\mathrm{d}}$, the concentration peaked in the lower half of the riser and there was a concentration minimum in the upper part $\left(x_{\mathrm{d}}=0.85\right)$ of the downcomer. Figs. 13 and 14 are for the aeration velocity of $3.7 \times 10^{-2} \mathrm{~m} \mathrm{~s}^{-1}$. At the higher aeration rate, the best-fit $x_{\mathrm{r}}$ and $x_{\mathrm{d}}$ values were 0.33 and 0.95, respectively (see caption of Fig. 4); hence, increasing

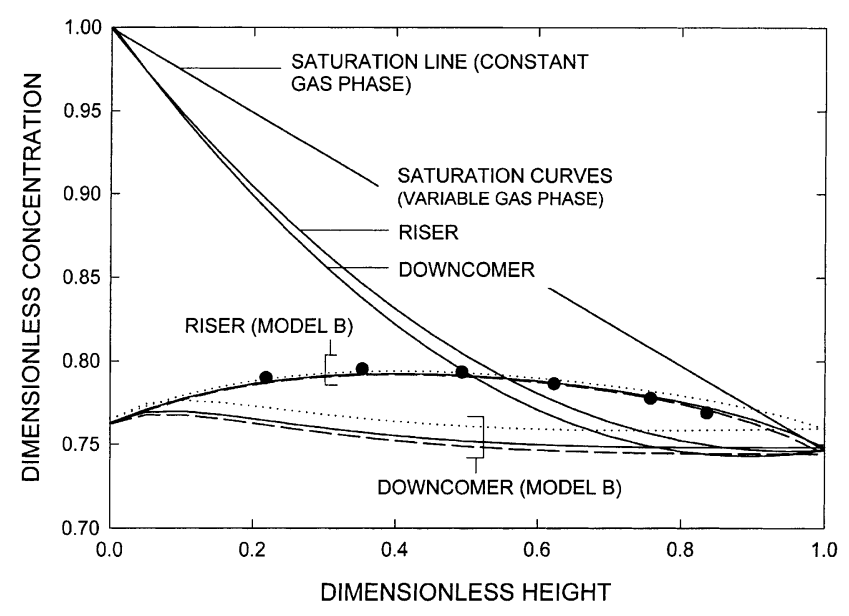

Fig. 14. Axial profiles of dissolved oxygen at steady state in the airlift reactor $\left(U_{\mathrm{Gr}}=3.7 \times 10^{-2} \mathrm{~m} \mathrm{~s}^{-1}\right)$. The model-predicted curves are for $x_{\mathrm{d}}$ values of 0.75 (dotted), 0.85 (solid), and 0.95 (dashed). All other parameters are as in Fig. 3. aeration rate shifted the peak concentration point lower in the riser, but the concentration minimum moved nearer the top of the downcomer. Although $x_{\mathrm{d}}$ was used as a fitting parameter in this work, this need not be so if a measured concentration profile is available for the downcomer.

Although the hydrodynamics in the riser and the downcomer are interlinked, so far, there is no mechanistic relationship between values of dispersion coefficients in those zones. Except Eq. (49), no fundamental relationship has been established between the gas holdup values in the riser and the downcomer [2,26]. Similarly, there is no clear evidence regarding the value of the parameter $\psi$ (Eq. (46)); however, the overall gas-liquid volumetric mass transfer coefficient measured for the reactor as a whole can be treated as consisting of contributions from the riser and the downcomer zones [2,5,28]. Another definitive relationship is the continuity-determined connection (Eq. (52)) between the linear liquid velocities in the riser and the downcomer zones. In view of the uncertainties, a degree of reliance on empirically determined parameters is inevitable.

No measurements of the oxygen concentration could be made in the downcomer zone. (The dissolved oxygen probe assembly was too large to enter the downcomer without substantially affecting the induced liquid flow rate.) However, the axial concentration profiles in the downcomer are not necessarily identical to those in the riser as revealed, e.g., in Figs. 3 and 4. The hydrodynamics in the riser and the downcomer zones tend to be quite different; hence, the different profiles. As a rule, the liquid-phase in the downcomer of an airlift reactor is always substantially more quiescent than the liquid in the riser [5,8]. This is mainly because of a net energy loss from the liquid-to the gas-phase as the fluid moves down the downcomer [2,5]. The energy goes into compressing the gas. Because of relatively quiescent hydrodynamics and a lower gas holdup, the volumetric mass transfer coefficient may be somewhat lower in the downcomer than in the riser section. Similarly, a lower axial dispersion coefficient value is expected for the liquid-phase in the downcomer zone. All these differences affect the downcomer dissolved oxygen profiles. In keeping with prior observations [5,8], the downcomer was always noticeably less turbulent than the riser in both reactors. The visually observed average bubble size in the downcomer zone was always smaller than in the riser, as reported in the past also $[5,8]$.

In contrast to airlift reactors, the steady-state oxygen concentration profiles in bubble columns are less sensitive to changes in aeration rate [5,19]. According to published data [5], the dissolved oxygen profiles in an airlift reactor were greatly affected when the specific power input in the reactor changed by factor of 2.65 . In comparison, the profile in a geometrically similar bubble column was only slightly affected for a $\sim 29 \%$ greater change in the specific power input [5]. The principal difference between a bubble column and an airlift reactor is the induced liquid circulation in the latter. Liquid circulation rate is sensitive to the aeration rate; 
hence, the specific power input has a stronger impact on the shape of the dissolved oxygen profile in an airlift vessel.

\section{Conclusions}

The steady-state concentration of dissolved oxygen varies axially in the risers and downcomers of tall airlift reactors. These axial concentration profiles are different than if Henry's law alone determined the profiles. The measured concentration profiles in the riser zone are closely correlated by models that combine hydrodynamics and mass transport effects. The shape of the axial concentration profile is influenced by several factors: the overall volumetric gas-liquid mass transfer coefficient, the axial dispersion coefficient, the liquid circulation velocity, and the superficial gas velocity. The profile is little affected by small changes in the overall gas holdup; however, the ratio of the riser and downcomer gas holdups affects the profile by influencing the liquid circulation rate. The following reactor geometry parameters affect the oxygen concentration profiles: the static height of liquid in the vessel, the cross-sectional areas of the riser and the downcomer channels, and the cross-sectional area available for flow under the baffle or the draft-tube. In view of these geometric influences, the design and scale of the reactor may significantly affect performance during biological treatment of wastewater.

The proposed models can be used to predict spatial variations in dissolved oxygen concentration in tall airlift bioreactors for other known operating parameters. In particular, the models provide useful tools for simulating the behavior of the reactor. How the various scale-dependent variables and operating parameters affect the spatial changes in dissolved oxygen can be predicted quantitatively in terms of the Peclet numbers in the riser and the downcomer zones, and the parameters $\gamma_{\mathrm{r}}, \gamma_{\mathrm{d}}, h_{\mathrm{D}}, \varepsilon_{\mathrm{Gr}}, \varepsilon_{\mathrm{Gd}}$, the density of the liquid, and the pressure in the headspace of the reactor. Such quantitative and detailed insight into the design-dependent operational performance of reactors is essential for effective use of airlift bioreactors in various processes. Evidence suggests that axial inhomogeneities in dissolved oxygen become more pronounced as the aeration rate increases in a tall airlift device. Potentially, axial inhomogeneities in concentration can be reduced by using multiple gas injection points along the height of the riser zone.

\section{References}

[1] J. Redman, Deep shaft treatment for sewage, Chem. Eng. (London) 441 (1987) 12-13.

[2] Y.

Chisti, Pneumatically agitated bioreactors in industrial and environmental bioprocessing: hydrodynamics, hydraulics and transport phenomena, Appl. Mech. Rev. 51 (1998) 33-112.

[3] R. Opie, Repeat order, World Water and Environmental Engineer, January/February, 1993, pp. 16-17.
[4] M.A. Winkler, Biological Treatment of Wastewater, Ellis Horwood, Chichester, UK, 1981, pp. 146-163.

[5] Y. Chisti, Airlift Bioreactors, Elsevier, London, 1989, 355 pp.

[6] A.B. Russell, C.R. Thomas, M.D. Lilly, Oxygen transfer measurements during yeast fermentations in a pilot scale airlift fermenter, Bioprocess. Eng. 12 (1995) 71-79.

[7] D.J. Pollard, A.P. Ison, P.A. Shamlou, M.D. Lilly, Reactor heterogeneity with Saccharopolyspora erythraea airlift fermentations, Biotechnol. Bioeng. 58 (1998) 453-463.

[8] Y. Chisti, M. Moo-Young, Airlift reactors: characteristics, applications and design considerations, Chem. Eng. Commun. 60 (1987) $195-242$.

[9] L.A. Glasgow, L.E. Erickson, C.H. Lee, S.A. Patel, Wall pressure fluctuations and bubble size distributions at several positions in an airlift fermentor, Chem. Eng. Commun. 29 (1984) 311-336.

[10] S. Fröhlich, M. Lotz, T. Korte, A. Lübbert, K. Schügerl, M. Seekamp, Characterization of a pilot plant airlift tower loop reactor. I. Evaluation of the phase properties with model media, Biotechnol. Bioeng. 38 (1991) 43-55.

[11] Y. Chisti, B. Halard, M. Moo-Young, Liquid circulation in airlift reactors, Chem. Eng. Sci. 43 (1988) 451-457.

[12] M.E. Abashar, U. Narsingh, A.E. Rouillard, R. Judd, Hydrodynamic flow regimes, gas holdup, and liquid circulation in airlift reactors, Ind. Eng. Chem. Res. 37 (1998) 1251-1259.

[13] J. Cai, T.J. Nieuwstad, Hydrodynamic modelling and blank running of a pilot-scale internal loop airlift reactor for wastewater treatment, Environ. Technol. 12 (1991) 637-653.

[14] K.H. Choi, W.K. Lee, Circulation liquid velocity, gas holdup and volumetric oxygen transfer coefficient in external-loop airlift reactors, J. Chem. Technol. Biotechnol. 56 (1993) 51-58.

[15] R.D. Fraser, G.A. Hill, Hydrodynamic characteristics of a spinning sparger, external loop airlift bioreactor, Can. J. Chem. Eng. 71 (1993) 419-425.

[16] M. Gavrilescu, R.Z. Tudose, Study of the liquid circulation velocity in external-loop airlift bioreactors, Bioprocess. Eng. 14 (1995) 33-39.

[17] D.L. Petrovic, D. Pošarac, A. Dudukovic, D. Skala, Hydrodynamics and mass transfer in a draft tube bubble column, J. Serb. Chem. Soc. 56 (1991) 227-240.

[18] D. Pošarac, D.L. Petrovic, Prediction of the gas holdup and liquid recirculation velocity in an external loop airlift reactor, J. Serb. Chem. Soc. 56 (1991) 359-369.

[19] F. Camacho Rubio, J.L. Garcia, E. Molina, Y. Chisti, Steady-state axial profiles of dissolved oxygen in tall bubble column bioreactors, Chem. Eng. Sci. 54 (1999) 1711-1723.

[20] P. Verlaan, A.M.M. Van Eijs, J. Tramper, K. Van't Riet, K.Ch.A.M. Luyben, Estimation of axial dispersion in individual sections of an airlift-loop reactor, Chem. Eng. Sci. 44 (1989) 1139-1146.

[21] W.-J. Lu, S.-J. Hwang, C.-M. Chang, Liquid mixing in internal loop airlift reactors, Ind. Eng. Chem. Res. 33 (1994) 2180-2186.

[22] Y. Bando, M. Nishimura, H. Sota, K. Toyoda, S. Suzuki, A. Idota, Flow characteristics of bubble column with perforated draft tube effects of equipment dimensions and gas dispersion, J. Chem. Eng. Jpn. 25 (1992) 49-54.

[23] J.-T. Wu, J.-Z. Jong, Liquid-phase dispersion in an airlift reactor with a net draft tube, Bioprocess. Eng. 11 (1994) 43-47.

[24] S. Wachi, H. Morikawa, K. Ueyama, Gas holdup and axial dispersion in gas liquid cocurrent bubble column, J. Chem. Eng. Jpn. 20 (1987) 309-316.

[25] C.S. Ho, L.E. Erickson, L.T. Fan, Modeling and simulation of oxygen transfer in airlift fermentors, Biotechnol. Bioeng. 19 (1977) 1503-1522.

[26] Y. Chisti, F. Wenge, M. Moo-Young, Relationship between riser and downcomer gas holdup in internal-loop airlift reactors without gas-liquid separators, Chem. Eng. J. 57 (1995) B7-B13.

[27] Y. Chisti, M. Moo-Young, Improve the performance of airlift reactors, Chem. Eng. Prog. 89 (6) (1993) 38-45.

[28] Y. Chisti, Mass transfer, in: M.C. Flickinger, S.W. Drew (Eds.), Encyclopedia of Bioprocess Technology: Fermentation, Biocatalysis, and Bioseparation, Vol. 3, Wiley, New York, pp. 1607-1640. 